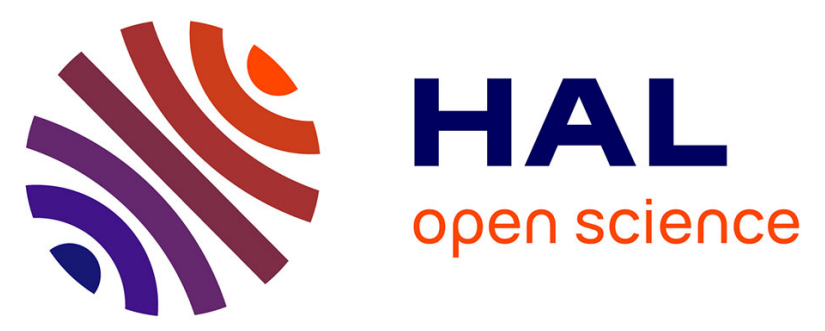

\title{
Morphologies of Cross-Linked Segmented Polyurethanes. Evolution during Maturation and Consequences on Elastic Properties and Thermal Compressive Fatigue
}

\author{
Pascal Pichon, Laurent David, Françoise Méchin, Henry Sautereau
}

\section{- To cite this version:}

Pascal Pichon, Laurent David, Françoise Méchin, Henry Sautereau. Morphologies of Cross-Linked Segmented Polyurethanes. Evolution during Maturation and Consequences on Elastic Properties and Thermal Compressive Fatigue. Macromolecules, 2010, 43 (4), pp.1888-1900. 10.1021/ma901602y . hal-02075249

\author{
HAL Id: hal-02075249 \\ https://hal.science/hal-02075249
}

Submitted on 21 Mar 2019

HAL is a multi-disciplinary open access archive for the deposit and dissemination of scientific research documents, whether they are published or not. The documents may come from teaching and research institutions in France or abroad, or from public or private research centers.
L'archive ouverte pluridisciplinaire HAL, est destinée au dépôt et à la diffusion de documents scientifiques de niveau recherche, publiés ou non, émanant des établissements d'enseignement et de recherche français ou étrangers, des laboratoires publics ou privés. 


\title{
Morphologies of Crosslinked Segmented Polyurethanes.
}

\section{Evolution during maturation and consequences on}

\section{Elastic Properties and Thermal Compressive Fatigue}

\author{
Pascal G. Pichon ${ }^{\dagger \S}$, Laurent David ${ }^{\dagger}$, Françoise Méchin ${ }^{\dagger}$, Henry Sautereau ${ }^{\dagger 1}$
}

†Université de Lyon, F-69003, Lyon, France; INSA Lyon, F-69621, Villeurbanne, France; Université Lyon 1, F-69622, Villeurbanne, France; CNRS, UMR5223, Ingénierie des Matériaux Polymères

${ }^{\S}$ Mérylithe SAS, rue Sommeiller, F-73420 Méry, France

pascal.pichon@insa-lyon.fr

Published in Macromolecules vol. 43, 1888-1900 (2010)

ABSTRACT: The solid state morphology evolution of a segmented polyurethane (SPU), with a crosslinked soft phase has been studied. Materials were cast with a small excess of isocyanate (6\%) and kept in time under atmospheric humidity at ambient temperature. Several analyses were performed on 2$\mathrm{mm}$ thick plates in order to determine structural evolutions with time (DSC, DMTA, AFM, TEM,

1 IMP/LMM and CNRS UMR 5223 Tel.: +33 472438178 ; Fax : +33 4724385 27. E-mail address: henry.sautereau@insa-lyon.fr, Tel.: +33 4724385 48. E-mail address: francoise.mechin@insa-lyon.fr. Tel.: +334724316 05. E-mail address: laurent.david@univ-lyon1.fr. 
SAXS) and their effects on static mechanical properties. SAXS experiments have been performed for mature samples and their analysis through different models enable to describe quantitatively the morphologies of hard segments with concomitant nodules and lamellae. The evolution of this morphology was monitored during maturation and heating ramps. For 2 mm-thick plates, a $15 \%$ modulus increase and a decrease in $\tan \delta$ at $120^{\circ} \mathrm{C}$ were obtained when the final properties were reached, 4 weeks after cure. It is presumably the result of the hydrolysis of free NCO groups to produce urea linkages at the border of the hard domains. Moreover as this SPU was developed for applications in fatigue, a specific compressive fatigue test at constant load was also designed to study the behavior of 39-mm diameter SPU cylinders under such stress (between 0.33 and $3.3 \mathrm{MPa}$ at $27 \mathrm{~Hz}$ ). Due to the viscoelastic behavior, a self-heating phenomenon was observed that could induce failure if the temperature reached the melting temperature of the hard segments. The fatigue behavior was improved during maturation, thanks to a decrease in the damping and a simultaneous increase in modulus. Unlike $2 \mathrm{~mm}$-thick plates, the final properties for 39-mm diameter cylinders were obtained only after a 13 -week maturation, presumably due to a thickness effect which delays the moisture diffusion. This maturation time was characterized by the stability of the structure and thus of fatigue properties.

Keywords: Crosslinked Segmented Polyurethane, maturation, thermomechanical fatigue, microphase separation, TEM, SAXS.

\section{Introduction}

Segmented polyurethanes (SPU) can be viewed as block copolymers with alternating soft and hard blocks. Due to thermodynamic immiscibility between both types of blocks, phase separation generally occurs and generates a two-phase morphology in these materials. However, because of the covalent links between segments, only a microphase separation is most often observed that is mainly influenced by the 
type and length of segments, sample composition and preparation ${ }^{1,2,3,4,5,6}$. For most elastomers, hard domains are present in limited amounts (below $\sim 40 \mathrm{wt} \%$ ). In this case they play the role of physical crosslinks and act as high modulus fillers dispersed in the low modulus soft matrix, whereas the soft phase provides extensibility to the material.

Chemically crosslinked polyurethanes can also be formed if a precursor with a functionality higher than 2 is present in the initial reacting system. These materials are said to have a better "shape memory"7 . The modulus, in the rubbery state at room temperature, is usually increased compared with linear materials, but in the same time the elongation at break significantly decreases because of additional covalent bonds that reduce the possible chain extension during tensile deformation. The crosslinking agent can be a tri- or higher-functional polyol, providing crosslinks in the soft phase; but it is also possible to use a polyisocyanate or a low molar mass crosslinking agent. However, this last method often leads to materials with altered microphase separation, or even single-phase materials with lower strengths ${ }^{8,9,10}$.

For many segmented polyurethane elastomers, it is well established that after the material was cast and cured, many properties change during the first few days or weeks of storage at room temperature, although this complex phenomenon is not fully understood. First, explanations involving a chemical process can be put forward since polyurethanes are usually obtained from reactive mixtures with a slight isocyanate excess, and the fate of these NCO functions can play a non-negligible role on the mechanical properties of the material. For example, Prisacariu et al. ${ }^{11}$ synthesized a SPU with a global index $[\mathrm{NCO}] /[\mathrm{OH}]=1.10$, in order to study the influence of chemistry on the maturation of PU materials. It is necessary here to differentiate "artificial ageing" of a material by specific immersion", under high temperature $^{13}$ or UV exposure, and chemical and/or physical changes at standard temperature and pressure, which is the case here. Prisacariu et al. ${ }^{11}$ demonstrated that the maturation of thin PU sheets was essentially due to the reaction of free NCO groups with air humidity to produce amine functions and finally urea groups. The consequence of this phenomenon was to enhance the material modulus. Using sheets with decreasing thicknesses, different consistant experiments showed that the time to reach final 
properties could be extrapolated to 12 days for an infinitely thin sample. This time increased with thickness because it was related with the time for water to diffuse inside the sample. In contrast for thicker samples, the slower production of allophanate groups by reaction of free NCO functions on neighboring urethanes took an increasing part. This reaction limited the final modulus of the material, presumably because an urea group could provide stronger or more numerous physical links (hydrogen bonds) than a simple allophanate branching point.

Apart from these slow chemical reactions in the solid state, physical rearrangements ${ }^{14}$ can also occur in the material during storage at room temperature, which can also account for its "maturation" and the slow variation in its macroscopic properties.

The material used in the present study was developed for thermomechanical fatigue applications. More precisely, the fatigue test was designed in agreement with an application in compression at a frequency of $27 \mathrm{~Hz}$. Elastomers are known to develop self-heating under cyclic loading ${ }^{15,16,17,18}$. Due to the viscoelastic response of the material, stress and strain are out of phase, creating a hysteretic loop over a full cycle. Part of the dissipated mechanical work is converted into heat and causes an increase in temperature inside the sample that can have in turn drastic effects on its mechanical properties and can finally induce a rupture of the material by melting of the hard segments (HS). The rest of the dissipated work could be assigned to changes in chain conformation and breaking-up of PU chains. In a similar study on polyurethane-urea samples ${ }^{19}$, this damage was shown to result essentially from the effect of temperature on the mechanical properties, since no change in chemical crosslink density of the soft matrix nor chain scission could be highlighted, although the rubbery modulus was shown to decrease.

The polyurethane elastomer used in this work was based on polyester (polycaprolactone, PCL) crosslinked soft segments and on a linear, high-melting temperature hard segment. For fatigue applications, it is indeed better to have linear hard segments for a better ordering of the hard domains and a better reinforcement effect ${ }^{20}$. In contrast, a high crosslink density in the soft matrix, e.g. with the use of a macrotriol precursor, limits permanent deformation under mechanical stress and avoids flowing and creep of the material as long as no chemical degradation occurs ${ }^{21,22}$. Finally, low NCO/OH ratios 
usually induce premature failure of fatigue-tested samples ${ }^{23}$. Thus, a little excess of NCO was used in this study to balance side reactions with humidity.

In the first part of this study, this mature segmented polyurethane, crosslinked in the soft phase, was thoroughly characterized to correlate morphology with mechanical properties, especially for an application in compressive fatigue.

The second part is devoted to morphology modifications during maturation at ambient temperature, without extra stress. Two geometries of material were studied. The maturation of 2-mm thick plates was followed by characterizing structural changes thanks to different experimental techniques (DSC, DMTA, AFM, TEM, SAXS). The consequences of these changes on mechanical properties were studied by static mechanical testing. At the same time the maturation of $39-\mathrm{mm}$ diameter cylinders was monitored using the same techniques and additionally by compressive fatigue testing, in order to establish correlations between the morphology of the material and its fatigue lifetime.

\section{Experimental Section}

\subsection{Materials}

The polyurethane studied in this work was synthesised via a two-step polymerization bulk process. The soft segment (SS) used is a mixture of two polyester oligomers derived from caprolactone, both terminated by primary hydroxyl groups and with an average molar mass of $2000 \mathrm{~g} / \mathrm{mol}$. The first one is a linear polycaprolactone (PCL) diol (CAPA® 2201 from Solvay) and represents 54 wt\% of the SS mixture. The second one is a PCL triol (CAPA® 3201) and represents $46 \mathrm{wt} \%$. Both have a melting temperature between 40 and $45^{\circ} \mathrm{C}$.

The hard segments (HS) were based on 4,4'-methylene bis(phenylisocyanate) (MDI) (Suprasec® 1100, Hunstman Polyurethanes) and hydroquinone bis( $\beta$-hydroxyethyl) ether (HQEE, Arch Chemicals). HQEE was preferred to 1,4-butanediol because of its higher incompatibility with polyester soft segments $^{24,25}$. The material contains $35 \mathrm{wt} \%$ (MDI-HQEE) hard segments, with a global NCO/OH index $=1.06$. The ShoreA hardness is 91 after maturation. 
Initially, the mixture was prepared at $120^{\circ} \mathrm{C}$ and was cast at low pressure (5 bars). Two geometries were cast in pre-heated moulds at $130^{\circ} \mathrm{C}$ : i) $200 \mathrm{~mm} \times 200 \mathrm{~mm}$ square plates of 2-mm thickness and ii) $500 \mathrm{~mm}$-long cylinders with a 39-mm diameter. Plates were used for all experiments, except fatigue tests, where 36-mm height cylindrical blocks were used. Those blocks were cut from the $500 \mathrm{~mm}$ long cylinders. $10 \mathrm{~mm}$-thick slides were also cut at each end and discarded to avoid any longitudinal structural gradient due to the steel mould. For the plates, due to their low thickness the obtained material had no morphological gradient. In contrast for the cylinders, the strong exothermal effect in this case (in fact, the temperature in the core of the cylinder reached $165^{\circ} \mathrm{C}$ ) led to a material with a radial gradient of structure and organization from core to shell, as revealed by DMTA and DSC experiments run to compare samples originating from different locations (see below). The cross-linked materials were obtained after 15 -hour curing at $130^{\circ} \mathrm{C}$. The analyses of the material were performed at different maturation times, during 23 weeks.

Model soft and hard segments were synthesised in order to study the purity of phases. The model soft segments were obtained from the PCL mixture (same as in the elastomer formulation) and MDI, and were synthesised in bulk at $80^{\circ} \mathrm{C}$ with a global index of 1.00 . The model hard segments MDI-HQEE were synthesised both in bulk at $130^{\circ} \mathrm{C}$ and at $30 \mathrm{wt} \%$ in solution (tetrahydrofuran, THF) at $50^{\circ} \mathrm{C}$, with use of dibutyltin dilaurate as a catalyst.

\subsection{Differential scanning calorimetry}

DSC measurements were carried out on a TA Instruments Q10 differential scanning calorimeter. The heating rate was $10^{\circ} \mathrm{C} / \mathrm{min}$ in the temperature range $-80 / 250^{\circ} \mathrm{C}$. The weight of the analyzed samples was close to 5mg; samples were taken from the cast plates, cylinder core and cylinder shell. For the hard segment model materials made in bulk and in THF, the samples were first molten at $260^{\circ} \mathrm{C}$, quenched to $-20^{\circ} \mathrm{C}$ (under the Tg of HS) and then studied during the second heating scan. 


\subsection{Dynamic mechanical thermal analysis}

DMTA experiments were carried out on a Rheometrics Solid Analyzer RSA II at $1 \mathrm{~Hz}$ at $0.1 \%$ tensile strain. The heating rate was $3^{\circ} \mathrm{C} / \mathrm{min}$ for the temperature range from -100 to $225^{\circ} \mathrm{C}$. The sample size cut from the cast plates was approximately $22 \times 4 \times 2 \mathrm{~mm}^{3}$. Other samples were cut from the shell and in the core of cylinders, in the longitudinal way.

\subsection{Small Angle $X$-Ray Scattering}

Small angle X-Ray scattering (SAXS) experiments were carried out at the ESRF (Grenoble, France) on the D2AM beamline. The incident photon energy was $16 \mathrm{keV}$. A bi-dimensional detector (CCD camera from Ropper Scientific) was used to collect the scattered radiation. The contribution of the empty cell was subtracted from the scattering images of the studied samples. The data were normalized with transmission, exposure time and thickness of the studied sample. The data were azimuthally averaged around the image center into a 1-D plot taking advantage of sample isotropy. A silver behenate standard with known diffraction peaks was used to calculate the scattering vector values $q$.

\subsection{Atomic Force and Transmission Electron Microscopy}

The samples were cut using an ultramicrotome Reichert equipped with a diamond knife, to obtain 60$\mathrm{nm}$ thick ultrathin sections. Samples were cut at $-100^{\circ} \mathrm{C}$. Cutting the material in the glassy state (below $\mathrm{Tg}_{\mathrm{SS}}$ ) enables to avoid major part of the deformation during cutting. Then, the sections were stained on copper grids with $\mathrm{RuO}_{4}$ vapors to enhance contrast between hard and soft phases before Transmission Electron Microscopy (TEM) observations. Samples were exposed during 10 to 15 minutes with a 2\%$\mathrm{RuO}_{4}$ solution. Observations were carried out on a Philips CM120 microscope at an accelerating voltage of $80 \mathrm{keV}$. The surface morphologies of these unstained samples were also observed in contact mode in force modulation by Atomic Force Microscopy (AFM), using a Nanoscale IIIa Digital Instruments microscope. 


\subsection{Static mechanical properties / Tensile testing}

Uniaxial tensile measurements were carried out on a MTS 2/M electromechanical testing system at $22 \pm 1{ }^{\circ} \mathrm{C}$ and $50 \pm 5 \%$ relative humidity. ISO-type samples (ISO/R 527) were cut with a $20 \mathrm{~mm}$ nominal gauge length and an approximately $2 \times 4 \mathrm{~mm}^{2}$ cross-sectional area. The test consists in 4 loads from 0 to $200 \%$ deformation with a crosshead speed of $300 \mathrm{~mm} / \mathrm{min}$ and unloads at $100 \mathrm{~mm} / \mathrm{min}$ in order to study the recovery and the Mullins effect ${ }^{26}$. A $5^{\text {th }}$ load was performed up to break. The secant modulus for $100 \%$ strain was determined by the mean value of 3 samples for each material and called $E_{100 \%}$. The loss work within a cycle is called W',

\subsection{Compressive fatigue testing}

Load-controlled fatigue tests were carried out on cylinders (39-mm diameter, 36-mm height) on a Zwick/Roell 1853 servo-hydraulic apparatus. The test consisted in a 3-hour sinusoidal loading from 400 to $4000 \mathrm{~N}$ (ie from 0.33 to $3.35 \mathrm{MPa}$, load ratio $\mathrm{R}=0.1$ ) at $27 \mathrm{~Hz}$. Different thermocouples were placed at different characteristic locations inside the sample to measure the temperature all along the compressive fatigue test. The strain, hysteretic loss, stress/strain phase shift angle and dynamic modulus were determined all along the fatigue experiment by recording groups of 10 cycles, 24 times per test.

\section{Results and Discussion}

\subsection{Morphological and mechanical characterization of mature SPU}

\subsubsection{2-mm thick plate}

Microphase separation between soft segments (SS) and hard segments (HS) leads to domains with a high HS content called hard domains (HD), while those with a high SS content are called soft domains (SD). The thermal transitions can be highlighted thanks to DSC experiments (Figure 1) ${ }^{1,27}$.

The soft phase is characterized by its glass transition at $\operatorname{Tg}_{S S}=-36.5^{\circ} \mathrm{C}$, and the hard domains by multiple endothermic melting peaks at $\mathrm{T}_{\mathrm{m} 1}=185^{\circ} \mathrm{C}$ and $\mathrm{T}_{\mathrm{m} 2}=205^{\circ} \mathrm{C}$. A broad endothermal 
phenomenon is also found at medium temperature (characterized by $\operatorname{Tr} \approx 53^{\circ} \mathrm{C}$ measured at the onset of the phenomenon), which could be associated either to the glass transition of the hard domains ${ }^{28,29}$, or to some "reorganization" among the hard segments ${ }^{3}$, and even to the mixing of soft and hard segments at the interfaces of the two phases ${ }^{30}$. Note that here a possible partial crystallization and melting of the PCL soft segments can be ruled out, since it would probably be observed at a lower temperature (in the range $20-40^{\circ} \mathrm{C}$ ) and also because the presence of short, branched PCL chains usually hampers crystallization $^{31}$.

In order to study the purity of phases and to better assess the observed transitions, model SSs and HSs were synthesised. A crosslinked $100 \%$ SS material was first obtained from the stoichiometric reaction of the PCL mixture with MDI and showed a sharp glass transition at $\operatorname{Tg}_{100 \% S S}=-48.5^{\circ} \mathrm{C}$. This crosslinked material was preferred to the mixtures of oligomers that could be obtained through the chemical modification of every $\mathrm{OH}$ chain end by a monoisocyanate to prevent polycaprolactone crystallization, and also to have a material closer to what could be a pure soft phase in the polyurethane elastomer.

The glass transition temperatures measured for the model HSs were $\operatorname{Tg}_{100 \% \mathrm{HS} \text { Bulk }}=112^{\circ} \mathrm{C}$ and $\mathrm{Tg}_{100 \% \mathrm{HS} \text { THF }}=102^{\circ} \mathrm{C}$ for the materials synthesised in bulk and in THF solution, respectively. The glass transition temperature is lower for the THF-route than in bulk, suggesting that the recovered HS chains were probably shorter in solution due to their early precipitation in $\mathrm{THF}$. This $\mathrm{Tg}$ is indeed very dependent on chain length. Above this glass transition temperature, both model HS samples also display sharp melting peaks at 217 and $249^{\circ} \mathrm{C}$, and even a third one at $261^{\circ} \mathrm{C}$ for the sample synthesized in THF solution. In the literature, Tonelli et al. ${ }^{32}$ also synthesized different model HSs based on MDI and HQEE and showed that discrete melting peaks with increasing melting temperatures could be associated with increasing oligomer lengths. These results are in good agreement with the proposed interpretation of the DSC thermograms in Figure 1.

Compared with the model soft phase, the soft matrix displays a slightly higher $\operatorname{Tg}\left(-36.5^{\circ} \mathrm{C}\right.$ instead of $48^{\circ} \mathrm{C}$ ). This might be due to some dissolved hard segments; but the presence of hard domains covalently linked with this soft matrix also induces the constraint of some "interfacial" soft segments and therefore 
an increase in their $\mathrm{Tg}$, and it is therefore difficult to distinguish between both effects. However the amount of dissolved hard segments, if any, must be rather low, i.e. $\leq$ the maximum value of $12 \mathrm{wt} \%$ that could be roughly evaluated using Fox's law (that neglects the above-mentioned constraint effect).

From these results, it can be assumed that the material is composed of two main phases: hard domains made up of partially organized (MDI-HQEE) linear hard segments; and a crosslinked soft phase, consisting of PCL soft segments and possibly dissolved hard segments. The transition at $\operatorname{Tr} \approx 53^{\circ} \mathrm{C}$ could be associated with the relaxation of an interphase between organized hard segments and soft matrix, or to the glass transition of other hard segments in an amorphous state.

The thermomechanical behavior of the mature plates of SPU was studied and is displayed in Figure 2. The mechanical transition of the soft phase is characterized by a strong relaxation with a damping maximum at $\mathrm{T} \alpha=-18.5^{\circ} \mathrm{C}(1 \mathrm{~Hz})$. This transition can be easily related to the glass transition temperature observed at $-36.5^{\circ} \mathrm{C}$ by DSC. The main $\alpha$ relaxation is followed by a smaller relaxation process close to $50^{\circ} \mathrm{C}(1 \mathrm{~Hz})$ (named T'r) in fair agreement with the weak phenomenon detected above $50^{\circ} \mathrm{C}$ (Tr) (Figure 1). Looking at this low loss of modulus, this transition could be associated with the glass transition of an amorphous hard phase. The rubber plateau is rather broad, extending from 0 to $170^{\circ} \mathrm{C}$ approximately, and allows a wide temperature range of use for the material. A minimum value of damping is observed between 100 and $150^{\circ} \mathrm{C}$. A second important drop in the modulus can be observed at the same temperature as that of the first endothermic peak in DSC (i.e. around $180^{\circ} \mathrm{C}$ ), followed by a third one around $200^{\circ} \mathrm{C}$, and could be associated with the beginning of disrupting of the order in the hard domains. Note that this material cannot flow, because of the crosslinked soft phase, which can be confirmed by the limited decrease in modulus after "melting" of the HD.

For tensile testing measurements (Figure 3), the raw material was at first loaded at $300 \mathrm{~mm} / \mathrm{min}$ to $200 \%$ deformation and then unloaded down to $0 \mathrm{~N}$ at $100 \mathrm{~mm} / \mathrm{min}$, i.e. an unloading speed of one-third of the loading speed. As expected, the rubbery behavior exhibits a high recovery capacity after tensile testing. The recovery is divided in two parts. The first part is an instantaneous recovery of $180 \%$, which also depends of the unloading speed. The second one is a non-elastic part of $15 \%$, which is almost 
entirely recovered after a few weeks at ambient temperature. At the end, $5 \%$ of the deformation is never recovered, denoting that this first deformation at $200 \%$ induced permanent morphological changes in the material (attributed by Christenson et al. ${ }^{33}$ to partly irreversible yielding and reorganization of the hard domains resulting in a highly oriented microfibrous morphology).

When a second load was run directly after the first cycle, an important decrease in stress, dissipated work and modulus was observed, here characterized by the evolution of the secant modulus at $100 \%$ real deformation, $E_{100 \%}$. As shown in Figure 3, $E_{100 \%}$ was calculated taking into account instantaneous unrecovered strain during loading. A Mullins effect is thus clearly evidenced ${ }^{26}$. The stress softening after the first loading cycle may be due to the rupture of the shortest soft segments ${ }^{33}$, or to the breaking-up of the intermolecular physical interactions in hard domains ${ }^{34}$. According to Christenson et al. ${ }^{33}$, further reloadings would only induce stretching of the soft segment matrix chains, resulting in the reversible realignment of the hard domains and restoring the microfibrillar morphology induced by the initial conditioning cycle.

Both modulus and loss work W' of the hysteresis loop were stabilized after 4 cycles, as shown in Table 1. The same conclusions could be drawn with cyclic compression ${ }^{35}$. The $5^{\text {th }}$ cycle was run up to break, and characterized the final properties of the material with a strain at break of $370 \%$ and a stress at break of $20 \mathrm{MPa}$.

Microscopy revealed a complex multiscale morphology. First, AFM allowed observing mesoscale phase separation. A strong contrast between domains with higher and lower hardness was obtained in contact mode in force modulation (Figure 4). The softer zones presumably associated with the soft matrix appear lighter; whereas harder, more or less spherical zones appear darker, with a mean diameter of 1 to $2 \mu \mathrm{m}$. These domains can be either isolated or more aggregated and seem to look like the spherulitic soft/hard superstructures already observed by Aneja et al. ${ }^{36}$.

Using TEM, we could observe more precisely how these domains with higher hardness (not to be confused with the real PU "hard domains") were indeed structured (Figure 5a). They definitely look like spherulites ${ }^{33,36,37}$ where the crystalline phase would be made of HS lamellae and where the amorphous 
phase would mainly be the soft matrix. Lamellae have a thickness of around $10 \mathrm{~nm}$ and can reach 500 $\mathrm{nm}$ in length. However, looking at an even smaller scale (Figure 5b), some 10-nm diameter dark spheres can also be observed in the soft phase. They could be attributed to HS nodules, either organized or completely amorphous.

Pseudo-quantitative analyses of TEM pictures were rather difficult but nevertheless showed that HD spherulites represent around 50\% of the surface area. These spherulites seem to be composed of around $20 \%$ lamellae and $80 \%$ soft phase. This means that lamellae would represent approximately $10 \%$ of the total surface area of the image. Note that this rough approximation only takes into account the lamellae that stand more or less perpendicular to the image and not those lying parallel to the image, and therefore obviously underestimates the real area occupied by these lamellae, also because the limit between lamellae and soft phase is hard to define in pictures. The other $50 \%$ of the analyzed surface can be associated with the soft matrix, which contains a few dissolved HS and some dispersed HS nodules.

In first approximation and assuming that the density of both HD lamellae and soft matrix is 1 , the amounts of HS organized in the lamellae (10\%) and of maybe a few HS dissolved in the soft phase represent less than $15 \mathrm{wt} \%$. Even if the amount contained in lamellae is underestimated, this result probably does not match with the global formulation that contains $35 \mathrm{wt} \%$ of HS. Therefore, HSs organized in the form of nodules must also be taken into account and will be studied further by SAXS in Part 3.1.3. These nodules could be composed of amorphous HS and then explain the phenomenon observed by DSC at $\mathrm{T}=\mathrm{Tr}$, and the associated mechanical relaxation observed by DMTA at T=T'r, which could be attributed to the glass transition temperature of these amorphous hard domains.

\subsubsection{Morphological and mechanical characterization of 39-mm diameter cylinders}

During casting, the higher exothermal effect observed in the core of the cylinder reached around $165^{\circ} \mathrm{C}$, while the center of the plate remained at about $130^{\circ} \mathrm{C}$. In the following, in order to study the effect of geometry on morphology, plates were compared with the shell and the core of cylinders. 
TEM analyses were also carried on the core and shell of a cylinder. Morphologies also consist of lamellae in spherulitic structures and nodules in the soft matrix, like for plates. TEM did not allow differentiating clearly the shell and the core of the cylinder, even after the determination of the characteristic sizes of lamellae and nodules, because TEM is a too local technique.

Results of DMTA experiments are reported in Figure 6 and Table 2 and results of DSC experiments in Figure 1 and Table 3. The thermal and thermo-mechanical behaviors of the shell of the cylinder are indeed similar to that of the plate, consistently with the fact that both materials were in contact with the mold at $130^{\circ} \mathrm{C}$. Contrary to plates and cylinders' shell, the cylinder core exhibits a different behavior. The $\mathrm{Tg}_{\mathrm{SS}}$ (in DSC) and T $\alpha$ (in DMTA) are roughly unchanged, evidencing that the amount of HS dissolved in the soft phase should be the same. But the value of the magnitude of $\tan \delta$ at T $\alpha$ is clearly higher in the core (0.61), showing that it contains more soft phase.

As for the hard domains, DSC thermograms show that their melting temperatures are higher but in the same time that the global melting enthalpy is lower. The modulus E' is smaller at $140^{\circ} \mathrm{C}$ for the core $(27$ MPa to compare with 43 for plates). This evidences that the core contains a smaller amount of ordered HSs in lamellae $\left(\Delta \mathrm{H}_{\mathrm{m} 1+2}\right.$ is smaller), but better organized $\left(\mathrm{T}_{\mathrm{m} 1}\right.$ and $\mathrm{T}_{\mathrm{m} 2}$ are higher).

The modulus E' is smaller at $22^{\circ} \mathrm{C}$ for the core (37 MPa to compare with 47 for plates). It might be linked with the smaller quantity of lamellae.

In DMTA, the decrease in conservation modulus E' observed at intermediate temperature is supposed to be due to the glass transition of amorphous HS. This decrease, calculated between 22 and $140^{\circ} \mathrm{C}$ (Table 2), is higher for cylinders' core ( - $11 \mathrm{MPa}$ ) than for plates ( - $7 \mathrm{MPa})$ and cylinders' shell (- 6 MPa). This could show that the core contains more amorphous HSs with nodules shape, but could also simply be the result of the lesser amount of lamellae, as confirmed by the value of $\Delta \mathrm{H}_{\mathrm{m} 1+2}$ (see Table 3 ). This balance should be related with the thermal history: during polymerization, the exothermy to $165^{\circ} \mathrm{C}$ favored the formation of amorphous nodules against organized lamellae.

Load-controlled compression fatigue experiments were carried out on SPU cylinders in vertical position. Part of the mechanical work is dissipated due to the viscoelastic effects and can be determined 
for each cycle as the hysteresis loop area (Figure 7). The evolution of the dynamic modulus $\mathrm{E}_{\mathrm{dyn}}$, the dissipated work $\mathrm{W}$ ' and the damping factor $\tan \delta$ (at $27 \mathrm{~Hz}$ ) can be recorded during the fatigue test.

In case the load-controlled test is performed in the linear viscoelastic domain, i.e. for very low strains, the dissipated work per second and per unit volume $\mathrm{W}^{\prime \prime}\left(\mathrm{W} / \mathrm{m}^{3}\right)$ is related to test conditions (frequency $f$, nominal maximum stress $\sigma_{0}$ and stress ratio $\left.R=\sigma_{\min } / \sigma_{\max }=\sigma_{\min } / \sigma_{0}\right)$ according to the following equation ${ }^{15}$ :

$$
W^{\prime \prime}=(\pi / 4) \cdot \sigma_{0}^{2} \cdot(1-R)^{2} . J^{\prime \prime} \cdot f
$$

where $J^{\prime \prime}=\sin \delta / E_{d y n}$ is the loss compliance of the material. At $10 \%$ strain, the material is not in linear viscoelastic conditions but the equation (2) can still be used to comment on the variations of W'. Under the experimental loading conditions, an increase in temperature is observed in the tested specimen, especially in the center, due to a part of the dissipated work $\mathrm{W}$ "' in the hysteresis loop that is converted into heat and to pseudo adiabatic conditions in the specimen. The sample temperature can stabilize or not ${ }^{15}$, depending on test parameters, chemistry and processing, geometry, damping factor and maturation state. Holes were drilled in the sample in order to place thermocouples in different positions. They monitored either radial or longitudinal temperature gradients due to contact with air and/or steel grips. Figure 8 shows the temperature evolution for 4 different radial positions at mid-height (including the surface) and for the surrounding atmosphere: during fatigue testing the highest temperature is reached in the center of the sample, and $\mathrm{T}$ decreases regularly from the center to the edges.

In the particular example of a mature sample (Figure 8), the temperature in the center of the sample stabilized at $140^{\circ} \mathrm{C}$ in air at $22^{\circ} \mathrm{C}\left(\sigma_{0}=3.35 \mathrm{MPa} ; \mathrm{f}=27 \mathrm{~Hz} ; \tan \delta\left(22^{\circ} \mathrm{C}\right)=0.12 ; \mathrm{E}_{\mathrm{dyn}}=43 \mathrm{MPa}\right)$. 


\subsubsection{SAXS studies on both materials geometries}

SAXS is a well suited technique to study the morphology and the structural changes during maturation or mechanical testing ${ }^{5}$. Again, experiments were carried out on samples with both geometries (plates and cylinders). The experimental SAXS pattern (scattered intensity $I c$ vs the scattering vector $q=4 \pi \cdot \sin (\theta) / \lambda$ where $\lambda$ in the incident wavelength and $2 \theta$ is the scattering angle) of the core of a mature 39-mm diameter cylinder is plotted in Figure 9. The Lorentz factor corrected curve $\left(\right.$ Ic. $q^{2}$ vs $q$, Figure 10), in analogy with semi-crystalline materials with lamellar morphology ${ }^{38}$, clearly shows two distinct correlation distances with the appearance of a shoulder on the low- $q$ side of the main correlation peak.

The peak position can be related to the Bragg's spacing $d^{B}$ according to:

$$
d^{B}=\frac{2 \pi}{q_{\max }}
$$

where $q_{\max }$ is the $q$ value at the scattering peak maximum.

The peak at low $q$ is attributed to a morphology with a correlation distance $d_{1}^{B}$ of $\sim 200 \AA$ that is in good agreement with the lamellar stack periodicity as deduced from TEM images (Figure 5a). In the same way, the second peak with $d_{2}^{B}$ around $100 \AA$ can be attributed to the inter-nodules correlation distance. Some nodules, the biggest one, were evidenced by TEM with a diameter around $100 \AA$ (Figure $5 b)$.

The analysis of the HS nodules morphology was based on the Beaucage model ${ }^{39}$, and that of the HS lamellar microstructure with the 1-D autocorrelation function $\gamma_{1}(r)^{6}$. Alternative strategies could consist in applying the Zernike-Prins ${ }^{40,41}$ model for nodules, but no additional information about interfaces' quality could be assessed.

\section{i) nodules}

The scattering from two-phase systems can be represented as the product of the form factor, $P(q)$, and the structure factor, $S(q)^{39}$ :

$$
I(q)=P(q) \cdot S(q)
$$


where $P(q)$ is the shape factor and depends on both the size and shape of the scattering entities. $S(q)$ is the structure factor and depends on the relative positions of the scattering objects.

The form factor for non-anisometric scattering entities is given by the following equation ${ }^{39}$ :

$$
P(q)=G \cdot \exp \left(-\frac{q^{2} \cdot R_{g}{ }^{2}}{3}\right)+B\left[\frac{\left(\operatorname{erf}\left(q \cdot R_{g} / \sqrt{6}\right)\right)^{3}}{q}\right]^{P}
$$

where the first term can be recognized as the Guinier law for non-anisometric particles with gyration radius $R_{g}$, and $G$ is the scaling factor (proportional to the contrast factor and to the square of the mean particle volume). The second term is associated with the generalized Porod's power law. The error function $\operatorname{erf}(X)$ is twice the integral of the Gaussian distribution with a mean of 0 and a variance of $1 / 2$. $B$ is the scaling factor for power law at high $q$ and $P$ the exponent of Porod's law. In the case of welldefined interfaces, the exponent $P=4$; but lower values of $P$ can be related with some fractal geometry of the morphology, whereas values higher that 4 can be due to a diffuse interface between the nodules and the soft matrix.

The expression of the structure factor $S(\mathrm{q})$ for a collection of hard spheres was used semiphenomenologically, according to:

$$
S(q)=\frac{1}{1+k \cdot \theta(q)}
$$

where $0<k<6$ is a parameter reflecting the strength of correlation effects i.e. the periodicity of the structure $(k=0$ yields $\mathbf{S}(\mathrm{q})=0$ i.e. no inter-particle interferences, whereas a high $k$ value induces a sharp correlation peak), $\theta(q)$ is given by equation 6 and $d_{2}$ is the correlation distance between nodules:

$$
\theta(q)=3 \frac{\sin \left(q \cdot d_{2}\right)-q d \cdot \cos \left(q \cdot d_{2}\right)}{\left(q \cdot d_{2}\right)^{3}}
$$

The result of the Beaucage model is plotted in Figure 9 and 10 (dashed lines), and yields a good interpretation of the high q scattering range from $5.10^{-2}$ to $0.17 \AA^{-1}$. In the low $q$-range, the scattering is dominated by the contribution of the lamellar stacks (see below). According to equations 5 to 7 , the 
nodules have a mean gyration radius $R_{g}=30 \AA$ and a mean inter-nodule correlation distance $d_{2}=111 \AA$. As a result, the soft matrix is nanostructured with small nodules that are too small to be easily observed and measured by TEM. The generalized Porod's exponent $P=3.9$ is close to 4 , in agreement with a sharp interface between the hard nodules and the soft matrix, i.e. meaning that the microphase separation is clear at the nanoscale.

The data fit performed with Beaucage model is plotted with Lorentz factor correction in Figure 10. Bragg's law yields the same estimation of the correlation distance as given by Beaucage model ${ }^{41}$, i.e. $d_{2}^{B}=108 \AA$.

\section{ii) lamellar stack morphology characterization}

The net contribution of the lamellar stacks as deduced from the difference between the experimental scattering pattern and the scattered contribution from the nodules (eq. 5-7) is plotted in Figure 9 (dotted curve). The Lorentz-corrected plot shown in Figure 10 yields the long period as estimated from the Bragg's law, $d_{1}^{B}=220 \AA$.

The 1-D correlation function $\gamma_{1}(r)$ is classically used for stacked lamellae systems, and is well supported here by TEM experiments ${ }^{6}$ (Figure 5). The correlation function (Figure 11) was calculated from the cosine Fourier transform:

$$
\gamma_{1}(r)=\frac{1}{Q} \int_{0}^{\infty} I(q) q^{2} \cos (q r) \mathrm{d} q
$$

where $Q=\int_{0}^{\infty} I(q) q^{2} \mathrm{~d} q$ is the invariant so that $\gamma_{1}(0)=1 \cdot \gamma_{1}(r)$ exhibits a well defined maximum at a correlation distance (long period) close to $L_{p}=204 \AA$, in good agreement with direct estimation from the Bragg's law, $d_{1}^{B}=220 \AA$. The first maximum of the correlation function is strongly attenuated, an indication that the distribution in the long period distance is rather broad, and maybe because the number of lamellae within a stack is low. The minimum value $\alpha$ of the 1-D correlation function is related to the volume fraction $\Phi_{1}$ of hard segment phase within the stacks (spherulites), through: 


$$
\alpha=-\frac{\Phi_{1}}{1-\Phi_{1}}
$$

In practice, due to distribution effects, the obtained values for $\Phi_{1}$ can be interpreted as a lower bound for the intraspherulitic fraction of the lamellae. We still use this parameter qualitatively in order to compare morphologies. In the case of the core of the cylinder samples, $\Phi_{1} \sim 13 \%$ and represents the content of hard domains organized in lamellae in the spherulite-like domains (Figure 5a). This result is thus consistent with pseudo-quantitative analyses of TEM pictures, which showed that spherulites were composed of around 10\% lamellae (although this value also represents a lower estimation).

The same analysis was carried out for the 2 -mm thick plate. It was also used to study the radial morphology gradient of the cylinder, every $3 \mathrm{~mm}$ from the center to the shell (radius: $19.5 \mathrm{~mm}$ ). The results are shown in Table 4 and Table 5.

Consistently with the conclusions obtained with DSC and DMTA experiments, cylinder shell and plates have a very similar structural organization. Nevertheless, slight morphology differences can be evidenced in the cylinder from core to shell, in particular a higher correlation distance $d_{2}$ in the shell (from 108 to $117 \AA$ ). The higher exothermy of the reaction for thicker samples led to a slightly finer morphology of nodules in the core of the 39-mm diameter cylinders.

Unexpectedly, the intraspherulitic lamellae volume fraction $\Phi_{1}$ in the spherulites is slightly higher in the core. This can be understood if the core contains less spherulites, since calorimetry and viscoelasticity globally predict a smaller amount of HSs ordered in lamellae in the core.

In every case, $P$ the exponent of Porod's law is rather constant and equal to 3.9 evidencing a sharp nodule/soft matrix interface. The correlation degree $k$ is rather constant, around 0.8 , inducing a weak inter-nodules correlation.

SAXS experiments showed, at first for both geometries, an important peak corresponding to the presence of nodules in the material. TEM already clearly showed lamellae composed of organized HS. The transition at Tr in DSC, with mechanical consequences at T' $r$ in DMTA, is thus attributed to the glass transition of the amorphous hard nodules, $\mathrm{Tg}_{\mathrm{HS} 1}$ and is further discussed in the following part. 


\subsubsection{Morphological changes on heating in a mature 2-mm thick plate as characterized by DSC and in-situ SAXS experiments}

Looking that thermal history during polymerization has an impact on the morphology and the thermomechanical behavior, the effects of thermal cures on morphology were then studied.

The parameters deduced from the study of the thermogram of Figure 1 during the first heating up to $260^{\circ} \mathrm{C}$ (Sample 1) are summarized in Table 6. Additional DSC experiments were then carried out to study separately the four observed phenomenon $\left(\mathrm{Tg}_{\mathrm{SS}}, \mathrm{Tg}_{\mathrm{HS}}, \mathrm{T}_{\mathrm{m} 1}\right.$ and $\left.\mathrm{T}_{\mathrm{m} 2}\right)$. In order to study these transitions, different samples were first heated to 130,195 or $220^{\circ} \mathrm{C}$, cooled to $-80^{\circ} \mathrm{C}$ and then heated to $250^{\circ} \mathrm{C}$, with a constant heating or cooling rate of $10^{\circ} \mathrm{C} / \mathrm{min}$.

Sample 2 was first heated to $130^{\circ} \mathrm{C}$ (i.e. after the broad $\mathrm{Tg}_{\mathrm{HS}}$ ), then cooled to $-80^{\circ} \mathrm{C}$ and re-heated to $250^{\circ} \mathrm{C}$. The effects of the first thermal cycle up to $130^{\circ} \mathrm{C}$ were a slight increase in $\operatorname{Tg}_{S S}\left(+2^{\circ} \mathrm{C}\right)$ and in $\Delta \mathrm{C} \mathrm{p}_{\mathrm{SS}}$. The glass transition temperature $\mathrm{Tg}_{\mathrm{HS}}$ did not change. Melting peaks were unchanged. It can thus be assumed that during the first heating run, part of the nodules, composed of liquid amorphous HSs, dissolved in the soft phase. The remaining separated amorphous HSs are associated with the glass transition temperature $\operatorname{Tg}_{\mathrm{HS} 1}=54^{\circ} \mathrm{C}$. The fact that short $\mathrm{HSs}\left(\mathrm{Tg}_{\mathrm{HS}}=53^{\circ} \mathrm{C}\right.$ when $\operatorname{Tg}_{100 \% \mathrm{HS} \text { Bulk }}=112^{\circ} \mathrm{C}$ and $\mathrm{Tg}_{100 \% \mathrm{HS} \mathrm{THF}}=102^{\circ} \mathrm{C}$ ) dissolved in the soft phase evidences that the microphase mixing temperature of HSs with the soft phase $\mathrm{T}_{\mathrm{MMT}}$ (i.e. the temperature above which both kinds of segment become miscible) ${ }^{14,42}$ depends on the length of the hard segments and that that of these short HSs, $\mathrm{T}_{\mathrm{MMT1}}$, is below $130^{\circ} \mathrm{C}$.

Sample 3 was first heated to $195^{\circ} \mathrm{C}$ (after the end of the first melting endotherm at $\mathrm{T}_{\mathrm{m} 1}$ ), then cooled to $-80^{\circ} \mathrm{C}$ and re-heated to $250^{\circ} \mathrm{C}$. The increase in $\operatorname{Tg}_{S S}\left(+4^{\circ} \mathrm{C}\right)$ and in $\Delta \mathrm{Cp}_{S S}$ are higher than for sample 2 . Two different and low intense $\mathrm{Tg}_{\mathrm{HS}}$, at 52 and $103^{\circ} \mathrm{C}$, can be detected in the second heating run. The first melting peak $\mathrm{T}_{\mathrm{m} 1}$ disappeared while the second one $\mathrm{T}_{\mathrm{m} 2}$ was unchanged. Therefore as for sample 2 , part of the nodules dissolved in the soft phase, while the rest was observed at $\operatorname{Tg}_{\mathrm{HS} 1}=52^{\circ} \mathrm{C}$. Part of the more ordered and probably longer HSs that melted at $\mathrm{T}_{\mathrm{m} 1}$ were also dissolved, while the rest remained amorphous after the cooling at $10^{\circ} \mathrm{C} / \mathrm{min}$, and could be associated with the new glass transition at 
$\operatorname{Tg}_{\mathrm{HS} 2}=103^{\circ} \mathrm{C}$. The high value of $\operatorname{Tg}_{\mathrm{HS} 2}\left(103^{\circ} \mathrm{C}\right)$ is a sign that these HSs, previously organized in lamellae with $\mathrm{T}_{\mathrm{m} 1}=185^{\circ} \mathrm{C}$, were longer. The fact that part of these long HSs dissolved in the soft phase suggests that their microphase mixing temperature with the soft phase, $\mathrm{T}_{\text {MMT2 }}{ }^{14,42}$ is below $195^{\circ} \mathrm{C}$. The $\mathrm{T}_{\mathrm{m} 1}$ peak disappearance is a sign that no long HSs had enough time to reorganize during cooling at $10^{\circ} \mathrm{C} / \mathrm{min}$.

Sample 4 was first heated to $220^{\circ} \mathrm{C}$ (after the end of the second melting endotherm at $\mathrm{T}_{\mathrm{m} 2}$ ), then cooled to $-80^{\circ} \mathrm{C}$ and re-heated to $250^{\circ} \mathrm{C}$. The increase in $\operatorname{Tg}_{S S}\left(+7^{\circ} \mathrm{C}\right)$ and in $\Delta \mathrm{Cp}_{S S}$ are higher again. In this case there is only one intense and broad $\mathrm{Tg}_{\mathrm{HS}}$, centered at $66^{\circ} \mathrm{C}$, which is a sign that it probably corresponds to many different HSs lengths. Both melting peaks $\mathrm{T}_{\mathrm{m} 1}$ and $\mathrm{T}_{\mathrm{m} 2}$ disappeared, meaning that a total melting of the organized HS is obtained. Here again, the total amount of dissolved HSs in the soft phase increased and no organized HSs would remain in the material.

To go a step further, an in situ SAXS experiment was also carried out to study the structural changes of a mature 2-mm thick plate with increasing temperature, from 30 to $250^{\circ} \mathrm{C}$ at $3^{\circ} \mathrm{C} / \mathrm{min}$. The exposure time was set to obtain 1 diffractogramm every $1.5^{\circ} \mathrm{C}$ (i.e. every $30 \mathrm{~s}$ ). We applied the modeling and determined the size and distance between nodules centers with the Beaucage approach $\left(\mathrm{d}_{2}\right)($ as described in Figure 9 for cylinder core). The long period of lamellar stacks was obtained thanks to Bragg's law on Lorentz-corrected pattern $\left(\mathrm{d}_{1}{ }^{\mathrm{B}}\right.$ ) (as in Figure 10 for the core). The variation of both distances with temperature is plotted in

Figure 12, and the intensity of both peaks in Lorentz-corrected spectra is shown in Figure 13.

For a two-phase system ${ }^{42}$, the intensity of the maximum is related to the microphase separation degree, $\bar{\eta}^{2}$ through:

$$
\bar{\eta}^{2}=\Phi_{H} \cdot \Phi_{S} \cdot\left(\rho_{H}-\rho_{S}\right)^{2}
$$

where $\rho_{i}$ and $\Phi_{i}$ are the electron density and volume fraction of each phase, respectively hard and soft phase. 
Different key temperatures are observed on both figures, which are 55, 90, 175 and $200^{\circ} \mathrm{C}$. Values for these key temperatures are reported in Table 7.

From 30 to $55^{\circ} \mathrm{C}$ (nodules). The distance between nodule centers, $d_{2}$ and the mean nodule radius, $R_{g}$ increase according to thermal expansion. The coefficient of thermal linear expansion is equal to $240.10^{-}$ ${ }^{6} /{ }^{\circ} \mathrm{C}$ and was determined thanks to the adjustement of position of the zero load during heating in DMTA. The soft phase expands more rapidly than the hard nodules because $\mathrm{T}>\mathrm{Tg}_{\mathrm{SS}}$ and $\mathrm{T}<\mathrm{Tg} \mathrm{H}_{\mathrm{HS}}$. The electron density is higher for nodules than for the soft phase, and it decreases more rapidly in the soft phase so that the term $\left(\rho_{H}-\rho_{S}\right)^{2}$ should increase when temperature increases. The volume fractions of phases should not change, so the integrated intensity of the contribution of the nodule increases, as seen experimentally.

From 55 to $90^{\circ} \mathrm{C}$ (nodules). Since temperature now exceeds the glass transition temperature of the nodules (see Figure 2 presenting the glass transition relaxation at $\operatorname{Tr} 53^{\circ} \mathrm{C}$ ), the related morphology is now more sensitive to thermal treatment and we can observe a significant increase in $d_{2}$ and $R_{g}$. The internal structure of the nodules is also affected, with a leveling-off of the intensity of the scattering contribution of the nodules. This could be due to a decrease in the electron density within the nodules combined with the thermal expansion effect of the soft phase. Such electron density evolution is a classical manifestation of the glass transition, but could also be due to a partial dissolution of the smallest nodules in the soft phase, or the dissolution of soft segments in the nodules.

From 90 to $175^{\circ} \mathrm{C}$ (nodules). The morphology evolves similarly to the low temperature range between 30 and $55^{\circ} \mathrm{C}$ : The nodule correlation length $d_{2}$, the mean nodule radius $R_{g}$, and the intensity increase with the same slope as between 30 and $55^{\circ} \mathrm{C}$, i.e. according to thermal expansion only. SAXS measurements thus suggest that part of the nodules should dissolve below $90^{\circ} \mathrm{C}$, but another population of larger nodules remain stable up to $175^{\circ} \mathrm{C}$.

From 30 to $175^{\circ} \mathrm{C}$ (lamellae). No transition of the HSs organized in the form of lamellae can be observed in this temperature range. Both the distance $d_{2}{ }^{B}$ and the intensity associated with the lamellae 
contribution increase linearly due to the thermal expansion effect of the material, especially that of the soft phase between lamellae. The uncertainty in the evaluation of both the distance $d_{2}{ }^{B}$ and the intensity of the peak related to lamellar stack contribution is higher than for nodules because of the modeling by the Beaucage's law. This is in agreement with DSC results showing that thermal cycles up to $130^{\circ} \mathrm{C}$ had no influence on the melting peaks of lamellae, and thus the lamellar morphology is unchanged.

From 175 to $200^{\circ} \mathrm{C}$. The intensity of both scattering contributions of nodules and lamellae decreases and the correlation distances increase, consistently with their melting accompanied by a dissolution of additional HSs in the soft matrix (and suggesting that the micro-mixing transition temperature $\mathrm{T}_{\text {MMT2 }}$ would in fact be lower than $175^{\circ} \mathrm{C}$ ). The dissolution of the lamellae and the nodules start at the same temperature and follow similar variations. The multiplicity of the endotherms observed on Figure 1 should not be ascribed to the complexity of the morphology with the concomitant presence of the nodules and lamellae.

Beyond $200^{\circ} \mathrm{C}$. Both the decrease in intensity and the increase in long distances speed up. The diffractograms can no longer be exploited beyond $215^{\circ} \mathrm{C}$ because the difference in electron density between phases is too low.

Considering 2 lengths of HSs, the shortest $\left(\mathrm{Tg}_{\mathrm{HS} 1}=53^{\circ} \mathrm{C}\right)$ would have a low $\mathrm{T}_{\mathrm{MMT1}}$ and would dissolve in the soft matrix as soon as $\mathrm{Tg}_{\mathrm{HS} 1}$ is reached, whereas the longest $\left(\mathrm{Tg}_{\mathrm{HS} 2}=103^{\circ} \mathrm{C}\right)$ would have a $\mathrm{T}_{\mathrm{MMT} 2}$ below $175^{\circ} \mathrm{C}$. The dissolution of nodules and lamellae starts at $175^{\circ} \mathrm{C}$ and is faster beyond $200^{\circ} \mathrm{C}$. Those two temperature domains can be correlated with the two endothermal peaks observed by DSC in the same temperature range.

To conclude about the structure of the mature SPU, it can be stated at first that for both geometries, around half of the material is composed of spherulites. In these, lamellae represent a volume fraction around $13 \%$, with a long period of around $200 \AA$. The rest of the material is the soft matrix. It may contain some dissolved hard segments. This soft matrix is also nanostructured with small amorphous hard nodules with a typical correlation distance close to $110 \AA$. The transition $\operatorname{Tr}$ is attributed to the glass transition of the amorphous hard nodules $\operatorname{Tg}_{\mathrm{HS} 1}$. 


\subsection{Evolution of structure and properties along maturation}

The aim of this part is to study if maturation at ambient temperature (from 0.5 to 23 weeks at $22^{\circ} \mathrm{C}$ and $50 \%$ relative humidity after the material was cast and immediately cured $15 \mathrm{~h}$ at $130^{\circ} \mathrm{C}$ ) can change the morphology and then influence the mechanical properties.

The modifications in the 2-mm thick plates were followed through structural and static mechanical properties evolutions. The 39-mm diameter cylinder's maturation was followed by means of DMTA analyses of both core and shell samples and fatigue testing.

\subsubsection{Structural changes during maturation and mechanical consequences on 2 -mm thick plates}

Different techniques (DSC, DMTA, tensile testing and SAXS) were used to follow the structural maturation and its mechanical effects for the plates. For all these characterization techniques, the major modifications occurred during the first 4 weeks at ambient temperature. Experimentally, we studied a series of samples cast at $120^{\circ} \mathrm{C}$ in molds pre-heated at $130^{\circ} \mathrm{C}$ and cured $15 \mathrm{~h}$ at $130^{\circ} \mathrm{C}$. Concerning the elastic behaviour, a $15 \%$ increase in the modulus at $22^{\circ} \mathrm{C}$ was observed (Table 10). An important issue was then to follow the corresponding evolution in the structural organization.

\section{Nanoscale organization}

The Beaucage model results obtained by SAXS after 1 and 13 weeks maturation on 2-mm thick plates are listed in Table 11. No change in correlation distances for both lamellae and nodules could be evidenced. The mean radius of the nodules did not change significantly, nor the exponent $P$ of Porod's law.

\section{$\underline{\text { Soft Matrix }}$}

The evolution of the loss factor is shown in Figure 14-a) (DMTA at $1 \mathrm{~Hz}$ with results in Table 9). Both $\tan \delta$ peak temperature and magnitude, associated with the soft matrix, are constant. $\operatorname{The} \operatorname{Tg}_{\mathrm{SS}}$ is also constant as deduced from DSC (Table 8). This means that the composition of the soft phase should not be modified with maturation time and does not play a significant role in the modulus increase. 


\section{$\underline{\text { Structural modifications }}$}

The glass transition $\mathrm{Tg}_{\mathrm{HS}}$ of the amorphous hard nodules increased from 41 to $52^{\circ} \mathrm{C}$ during maturation. The temperature T'r of the slight decrease of modulus E' (Figure 14-b)) also increased during the first 4 weeks from 51 to $63^{\circ} \mathrm{C}$. The damping factor (DMTA at $1 \mathrm{~Hz}$ and $0.1 \%$ deformation) between 100 and $150^{\circ} \mathrm{C}$ decreased and finally the modulus $\mathrm{E}^{\prime}$ at $22^{\circ} \mathrm{C}$, and also at $140^{\circ} \mathrm{C}$, increased. In tensile testing, the modulus $E_{100 \%}$ also increased by $15 \%$.

The temperature of the first melting peak $\mathrm{T}_{\mathrm{m} 1}$ obtained in DSC increased, but not its integrated enthalpy. The temperature of the second peak, $\mathrm{T}_{\mathrm{m} 2}$, increased less than $\mathrm{T}_{\mathrm{m} 1}$ but its enthalpy $\Delta \mathrm{H}_{\mathrm{m} 2}$ also increased (Table 8). The combined evolutions of $E^{\prime}$ and $E^{\prime \prime}$ induced an increase in the loss work per tensile cycle $\mathrm{W}^{\prime \prime}$ in the $200 \%$ strain-controlled experiment (Table 10). Here again, these mechanical/thermal behavior changes occurred during the first 4 weeks.

\section{Chemical arguments}

Prisacariu et al. ${ }^{11}$ demonstrated that the maturation of thin PU sheets obtained with an initial $10 \%$ excess of isocyanate functions was essentially due to the reaction of free NCO groups with air humidity to produce amine functions and finally urea groups. This reaction was supposed to take place predominantly at the border of the hard domains because i) to produce an urea bond each of the 2 implied free NCO groups obviously belongs to some hard segment, and ii) because they also have to be close to one another (i.e. they must belong to the same hard domain); whereas the water molecules are supposed to diffuse through the continuous soft phase towards these hard domains. For these authors, the consequence of this phenomenon was to enhance the elastic modulus. However no precise information about the material morphology was given in this paper.

In the present work the $\mathrm{Tg}_{\mathrm{HS}}$ of the amorphous hard nodules was initially around $41^{\circ} \mathrm{C}$, whereas that of the model hard segments was equal to $112^{\circ} \mathrm{C}$, meaning that at least the HSs that constituted the surface of these nodules were short, having only a few repetitive units. If the hydrolysis of free NCO groups (initial excess : 6\%) also produced amine functions and finally urea linkages, the consequence could be an increase in the hard segments average length and then an increase in their $\mathrm{Tg}_{\mathrm{HS}}$, without 
changing the quality of interfaces with the soft matrix. Here the $\mathrm{Tg}_{\mathrm{HS}}$ of the amorphous nodules reached $52^{\circ} \mathrm{C}$ after 4 weeks maturation. This $\operatorname{Tg}_{\mathrm{HS}}$ is a little beyond ambient temperature. $\mathrm{At} \mathrm{Tg}_{\mathrm{HS}}$, nodules turn from a dispersed amorphous solid phase to a new separated liquid phase, since the micromixing temperature of long $\mathrm{HSs}, \mathrm{T}_{\mathrm{MMT2}}$ of the system, below $175^{\circ} \mathrm{C}$, is not reached.

Even if the same formation of ureas can occur at the border of lamellae, the increase in the melting enthalpy and modulus at $140^{\circ} \mathrm{C}$ cannot be explained by this reaction. The modulus would increase if urea linkages were created between the border of lamellae and the soft matrix. The probability of this reaction with free NCO in the soft matrix is small but can nevertheless be considered. The little increase in melting temperatures could be explained by a better ordering in the pseudo-organized lamellae. It may be associated with an increase of modulus. The decrease in damping between 100 and $150^{\circ} \mathrm{C}$ has is still to be explained.

\section{Final properties}

The stress at break is rather constant with maturation time, ranging from 26 to $22 \mathrm{MPa}$. The dispersion in the ultimate mechanical properties is large, but the global trend of the evolution of the strain at break is a significant decrease from $530 \%$ after 4 days maturation down to $410 \%$ after 13 weeks maturation.

Finally, the same maturation experiments carried out on samples kept in a perfectly dry atmosphere showed no evolution of the mechanical properties (both static and fatigue) after 3 weeks, evidencing that moisture is indeed necessary for the maturation process to be completed.

\subsubsection{Effect of sample thickness through 39-mm diameter cylinder fatigue behavior}

Results from DMTA analyses of the core of the cylinder along maturation are reported in Table 12. As for the plates, an important decrease was observed in the damping factor tan $\delta$ between 0 and $200^{\circ} \mathrm{C}$. Both modulus E' at $22^{\circ} \mathrm{C}$ and $140^{\circ} \mathrm{C}$ increased, but less than for plates. It is clear that maturation took a longer time and had less impact on modulus for the 39-mm diameter cylinder than for the 2-mm thick plate. It was then decided to follow the maturation of the cylinder by fatigue testing. 
After 4 weeks maturation at ambient temperature, the core material temperature does not yet stabilize during the fatigue testing experiment, and reaches the HD melting temperature where the modulus drops at $180^{\circ} \mathrm{C}$ (Figure 2). The sample cannot withstand the test and undergoes thermal failure.

Between 4 and 9 weeks of maturation time, as shown in Table 13, a slight increase in $\mathrm{E}_{\mathrm{dyn}}$ at $22^{\circ} \mathrm{C}$ and $140^{\circ} \mathrm{C}$, combined with a decrease in $\tan \delta$, limits the loss work $\mathrm{W}^{\prime}$ '. Thanks to these improvements, the material finally passes the fatigue test and the temperature in the sample core stabilizes after 30 minutes at $145^{\circ} \mathrm{C}$, as shown in Figure 8 .

Contrary to static mechanical experiments where $\mathrm{W}^{\prime \prime}$ increases when the modulus increases, it decreases in dynamic mechanical experiments. This difference is explained by the fact that fatigue testing is controlled in load, not in strain as tensile testing, and also that different maximum strains are reached in both tests (10\% in fatigue and $200 \%$ in tensile testing).

Between 9 and 23 weeks, almost no additional improvement is observed, meaning that the final properties are roughly achieved and that the mechanical effects of the maturation process are over. The core temperature stabilizes at $140^{\circ} \mathrm{C}$ both after 13 and 23 weeks, confirming that the final optimal properties of the 39-mm diameter cylinder were reached after 13 weeks.

This time to stabilize is much longer than for the 2-mm thick plate. It can be partially explained by the effect of the thickness of the sample. As mentioned by Prisacariu et al.11, the diffusion time of water determines the production of urea groups. But this time is however long enough to suppose that other reactions (like the formation of allophanates since a urethane group is always available in the vicinity of any free NCO group) and physical phenomena could occur to explain the maturation. The modulus was initially smaller in the core because it contains less lamella. The increase in modulus due to maturation is smaller for cylinders' core than for plates. Consistently with these observations, the formation of allophanate groups would give less stiffness to the material than urea linkages. 


\section{Conclusions}

A convergent analysis based on complementary characterization techniques (calorimetry, thermal mechanical analysis, microscopy, X-Ray measurements) was carried out to characterize the morphology of a segmented polyurethane PCL/MDI/HQEE crosslinked in the soft phase.

The evolution of the multiscale morphology of a 2-mm thick plate and its consequences on its static mechanical properties during a long maturation time at ambient temperature were studied (until 13 weeks) and showed that most part of the modification occurred during the first 4 weeks. No modification was observed in the soft phase. The hydrolysis of excess NCO groups to produce urea bonds in the border of amorphous hard nodules could increase the average chain length of the HSs and therefore the $\mathrm{Tg}$ of the amorphous hard domains. The increase in the modulus (at $140^{\circ} \mathrm{C}$ ) and melting enthalpy of organized lamellae could be explained by an increase in the number of crosslinks between lamellae and the soft matrix.

During this maturation, fatigue behavior of $39-\mathrm{mm}$ diameter cylinder also gets better thanks to the simultaneous damping decrease and modulus improvement. The time necessary to stabilize the properties of the material is around 13 weeks, which is much longer than for the 2-mm thick plate, confirming the thickness effect presented by Prisacariu et al. ${ }^{11}$. The core of the cylinder contains less lamellae and therefore has a smaller modulus.

Future work will be focused on the understanding of the key parameters which govern the fatigue behavior. A thermal modelling of the self-heating is also in progress to predict the equilibrium temperature reached by any sample with defined formulation, shape and size under cyclic compressive loading.

Acknowledgement The authors thank Pierre Alcouffe and the "Centre Technologique des Microstructures de l'Université Claude Bernard Lyon 1" for microscopy and the D2AM beamline, CRG group and local contact Cyrille Rochas at ESRF, Grenoble (France) for the SAXS measurements. 


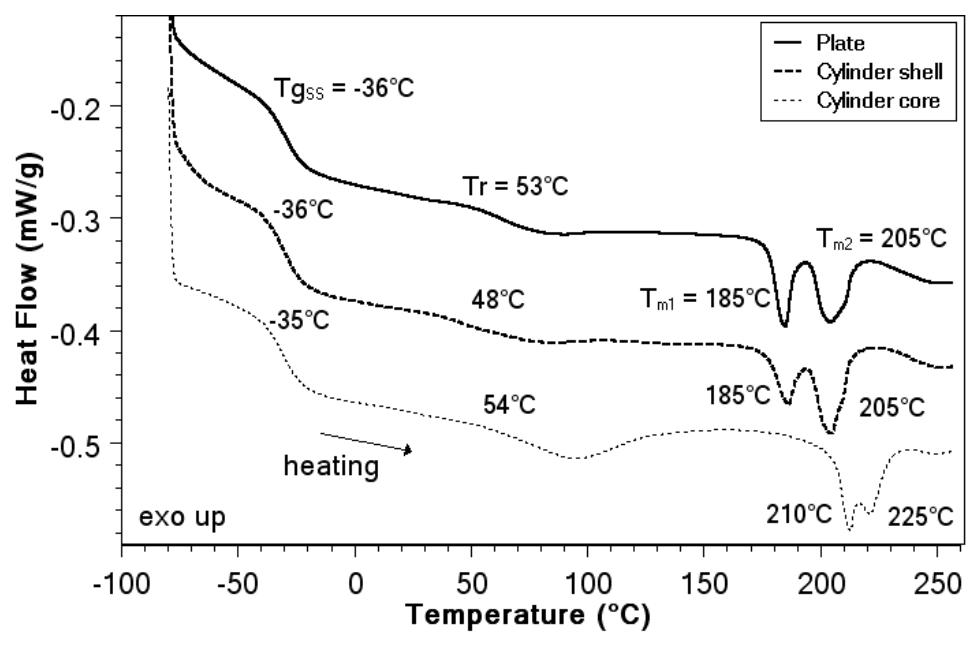

Figure 1. DSC thermogram of a mature $2-\mathrm{mm}$ thick plate, cylinder shell and cylinder core $\left(10^{\circ} \mathrm{C} / \mathrm{min}\right.$, first scan)

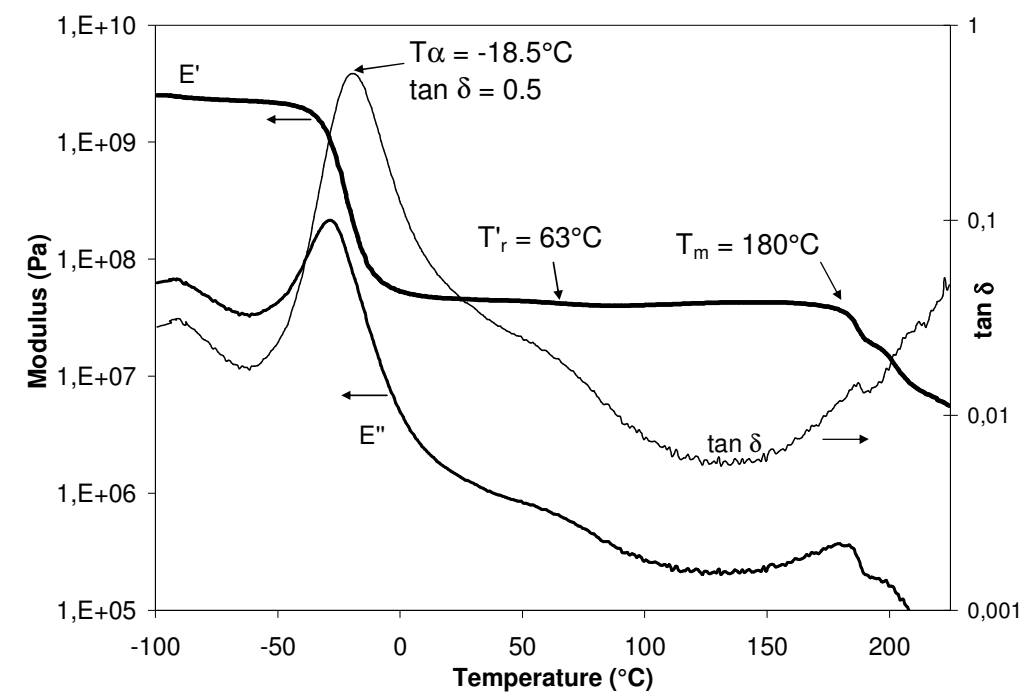

Figure 2. DMTA curves obtained on a mature 2-mm thick plate. (Testing conditions: $0.1 \%$ strain, heating rate: $3^{\circ} \mathrm{C} / \mathrm{min}$, frequency: $1 \mathrm{~Hz}$.). T'r is defined as the inflection point of the loss of modulus occurring between 50 and $100^{\circ} \mathrm{C}$. 


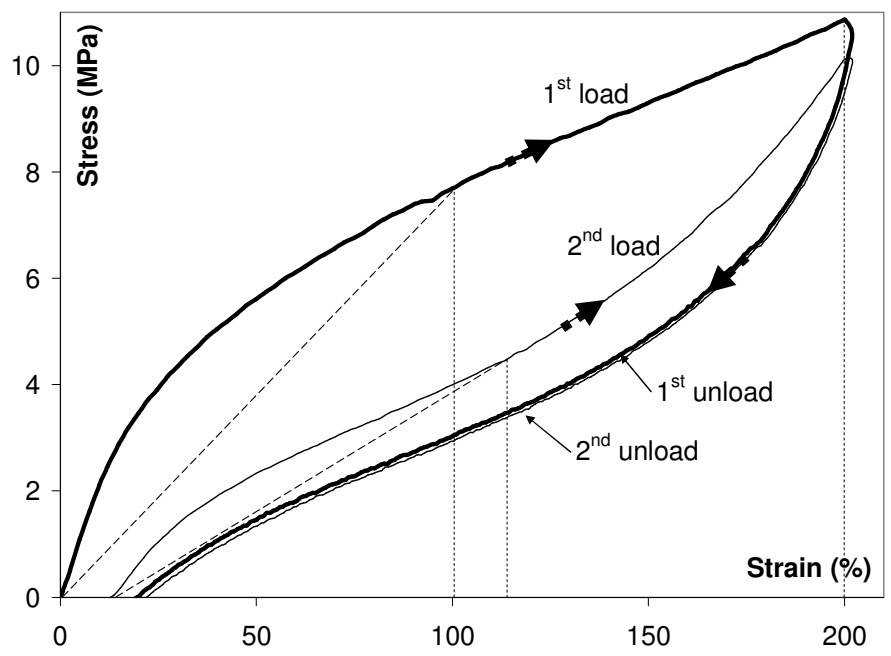

Figure 3. Static tensile tests of a mature $2-\mathrm{mm}$ thick plate at $22^{\circ} \mathrm{C} .1^{\text {st }}$ and $2^{\text {nd }}$ loads from 0 to $200 \%$ strain at $300 \mathrm{~mm} / \mathrm{min}$ and unloads back to $0 \mathrm{~N}$ at $100 \mathrm{~mm} / \mathrm{min}$.

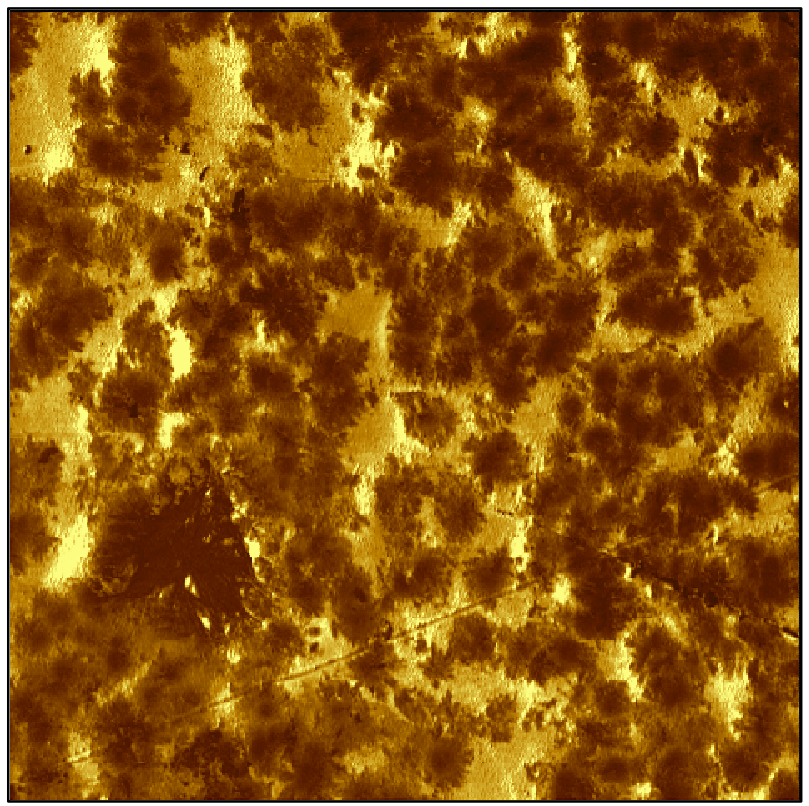

Figure 4. AFM $30 \times 30 \mu \mathrm{m}^{2}$ image of a mature 2-mm thick plate, in contact mode in force modulation. 


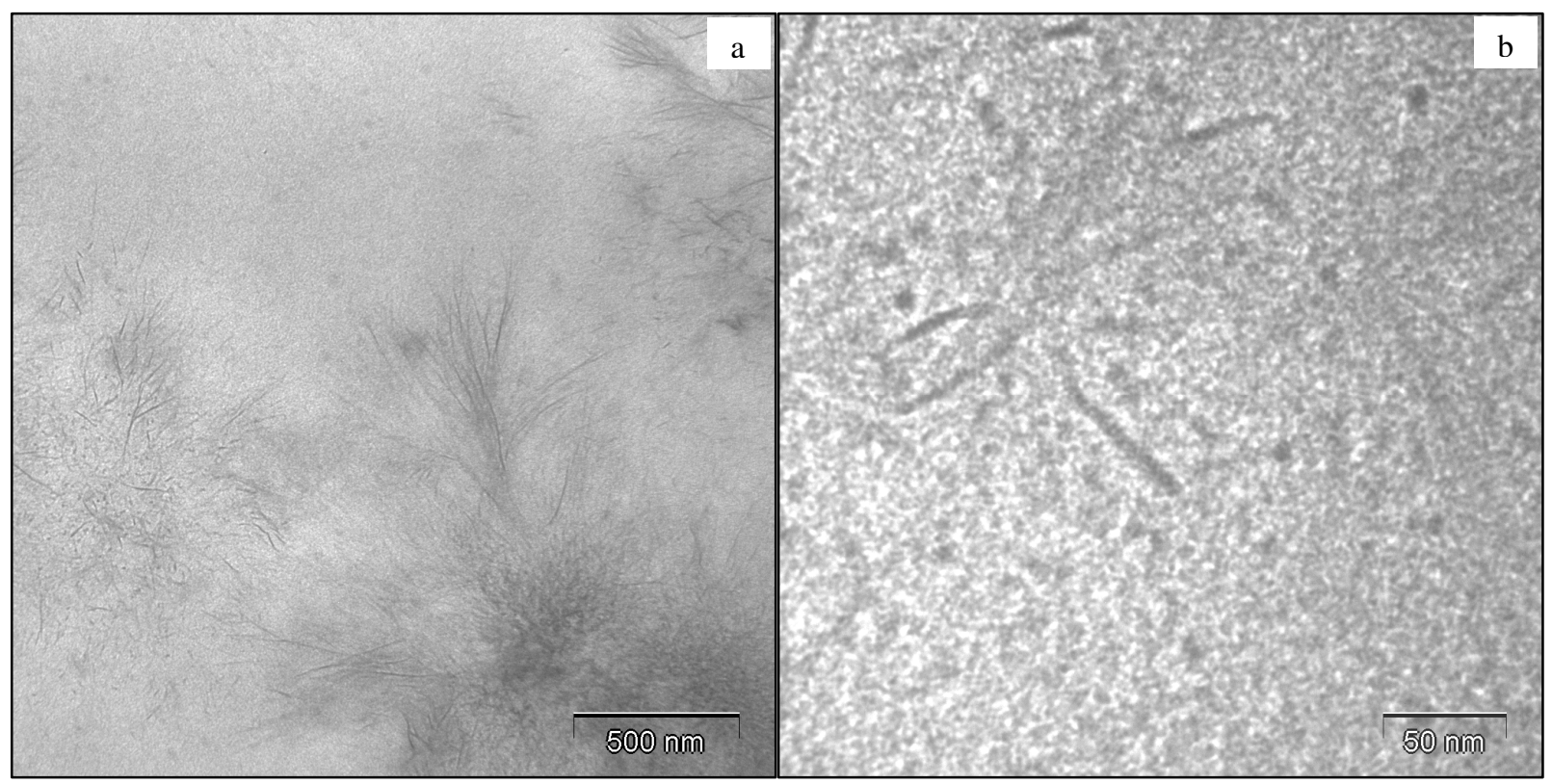

Figure 5. TEM micrographs of a mature 2-mm thick plate stained by $\mathrm{RuO}_{4}$ at two different scales.
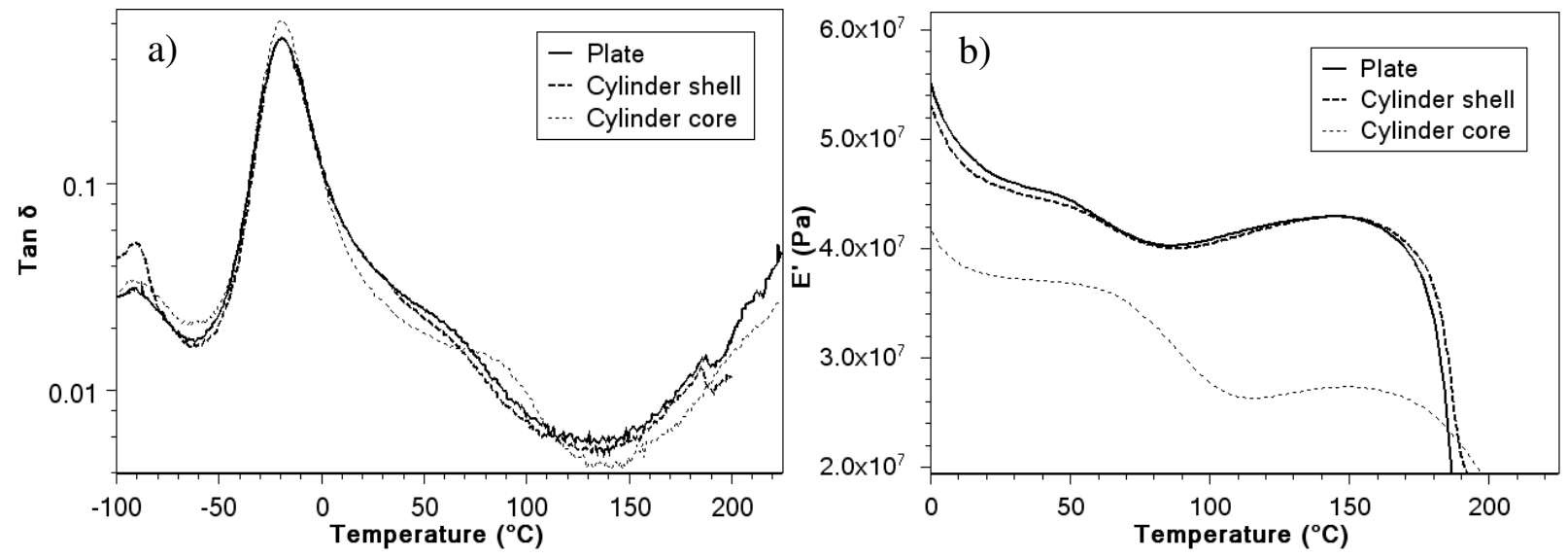

Figure 6. DMTA curves a) damping signal and b) elastic modulus E' obtained on a mature 2-mm thick plate, cylinder shell and cylinder core. (Testing conditions: $0.1 \%$ strain, heating rate: $3^{\circ} \mathrm{C} / \mathrm{min}$, frequency: 1Hz.). T'r is defined as the inflection point of the loss of modulus occurring between 50 and $100^{\circ} \mathrm{C}$ 


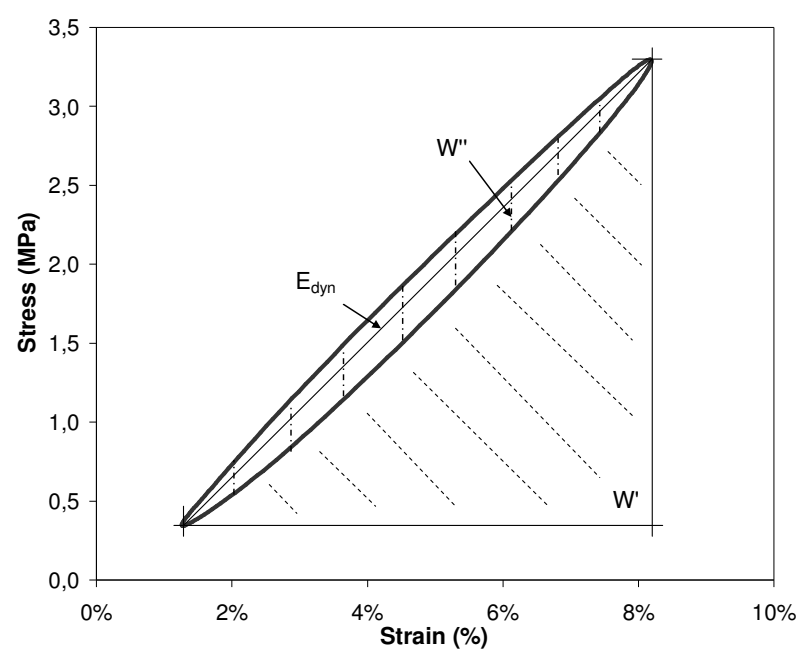

Figure 7. Example of a fatigue cycle on a mature $39-\mathrm{mm}$ diameter cylinder, at $\mathrm{T}=22^{\circ} \mathrm{C}$. The area of the hysteresis ellipse yields the work of the lost work per cycle, W', The dynamic modulus $\mathrm{E}_{\mathrm{dyn}}$ is defined as the slope of the cycle.

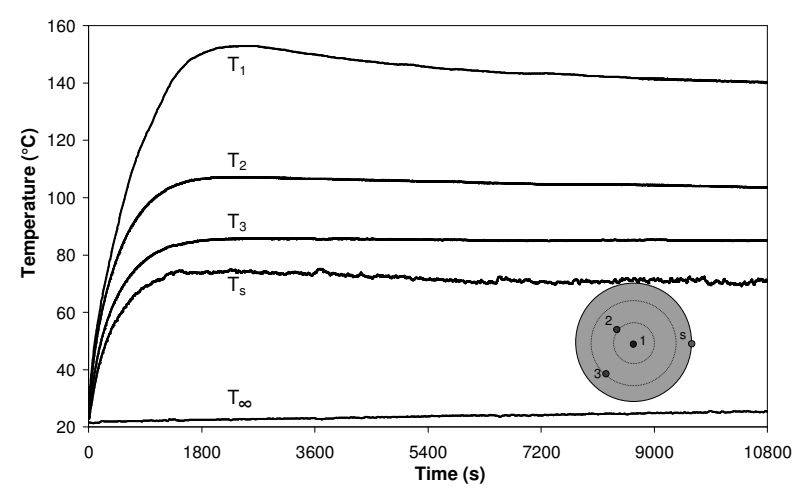

Figure 8. Evolution of temperatures in 4 different radial positions at mid-height of a mature 39-mm diameter cylinder ( $T_{1}$ at the center, $T_{2}$ at $6 \mathrm{~mm}$ from the center, $T_{3}$ at $12 \mathrm{~mm}$ from the center and $T_{s}$ on the surface) under compressive fatigue. Room temperature $\mathrm{T}_{\infty}$ is also represented. 


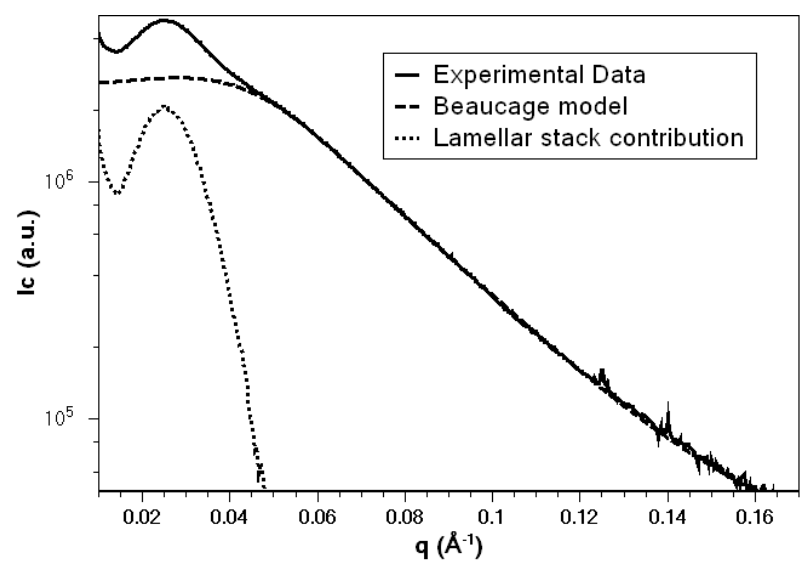

Figure 9. SAXS diagram (corrected intensity Ic vs scattering vector $q$ ) of the core of a mature 39-mm diameter PU cylinder. Results of Beaucage model are summarized in Table 4.

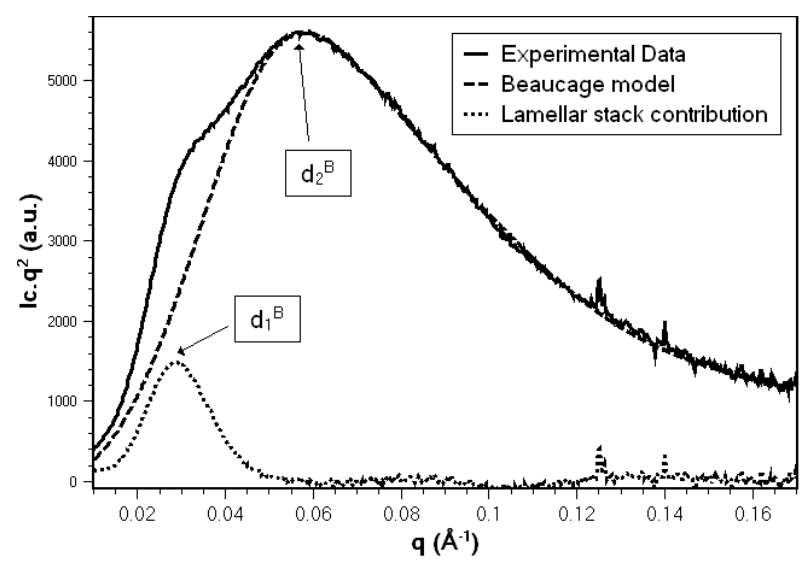

Figure 10. Lorentz-corrected SAXS intensity spectrum of the core of a mature 39-mm diameter cylinder, shown in Figure 9, as a function of scattering vector q. Results of Bragg's law are summarized in Table 5 . 


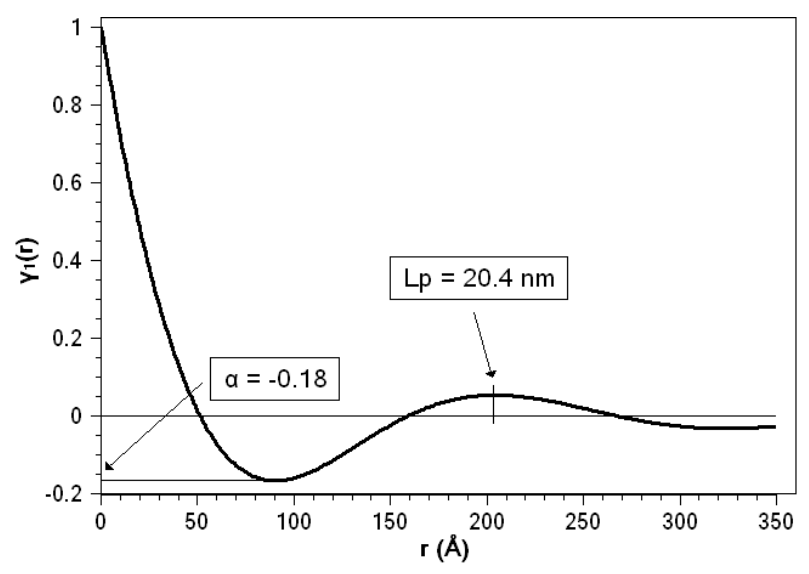

Figure 11. 1-D correlation function obtained from the lamellae contribution shown in Figure 9 (dotted line). Results are summarized in Table 5.

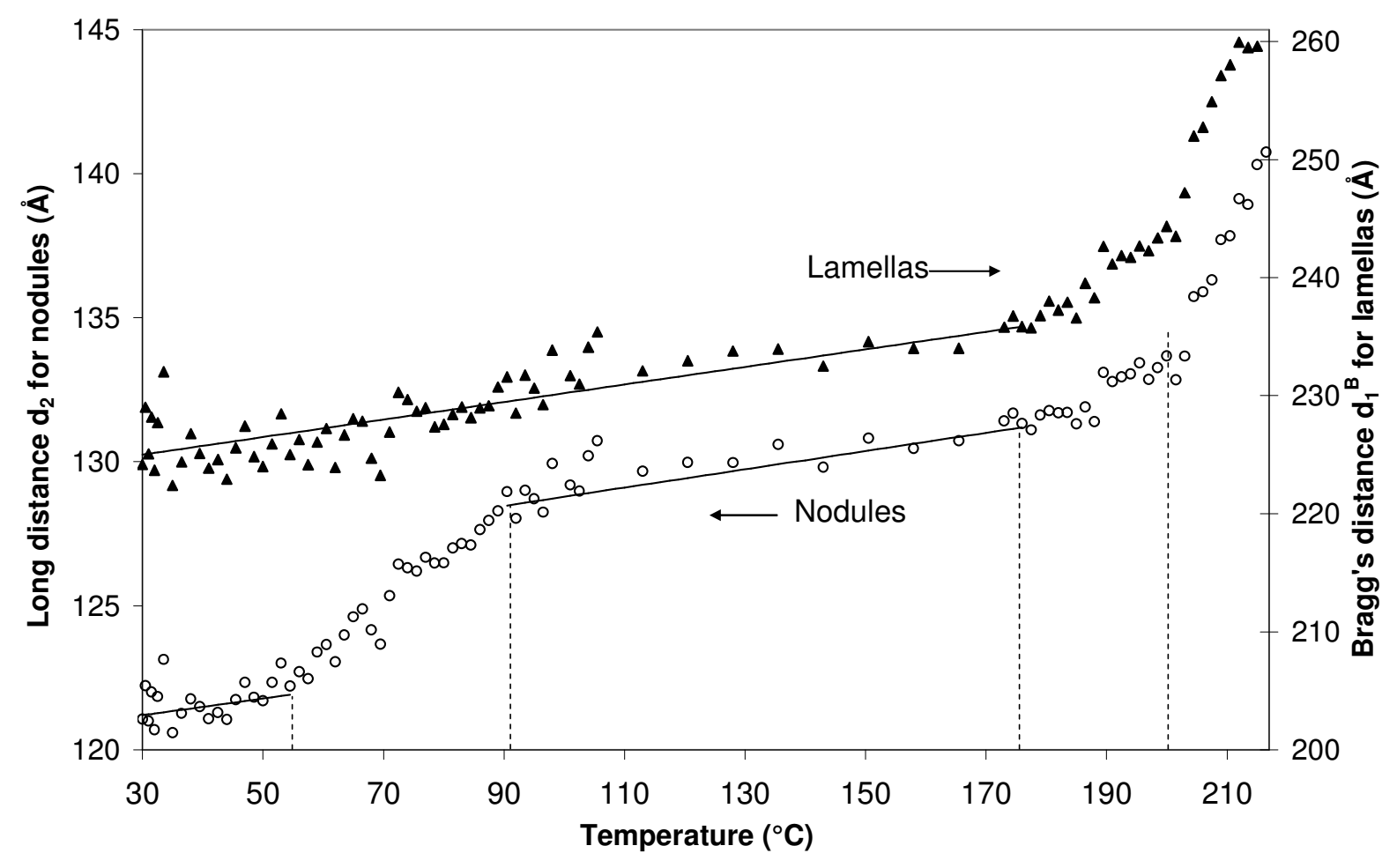

Figure 12._Correlation distances extracted from Beaucage model for spheres and from Bragg's law on Lorentz-corrected scattering patterns for lamellae during in-situ SAXS experiments on a mature 2-mm thick plate with temperature, from 30 to $250^{\circ} \mathrm{C}$, at $3^{\circ} \mathrm{C} / \mathrm{min}$ ( 1 data acquisition every $1.5^{\circ} \mathrm{C}$ or $30 \mathrm{~s}$ ). 


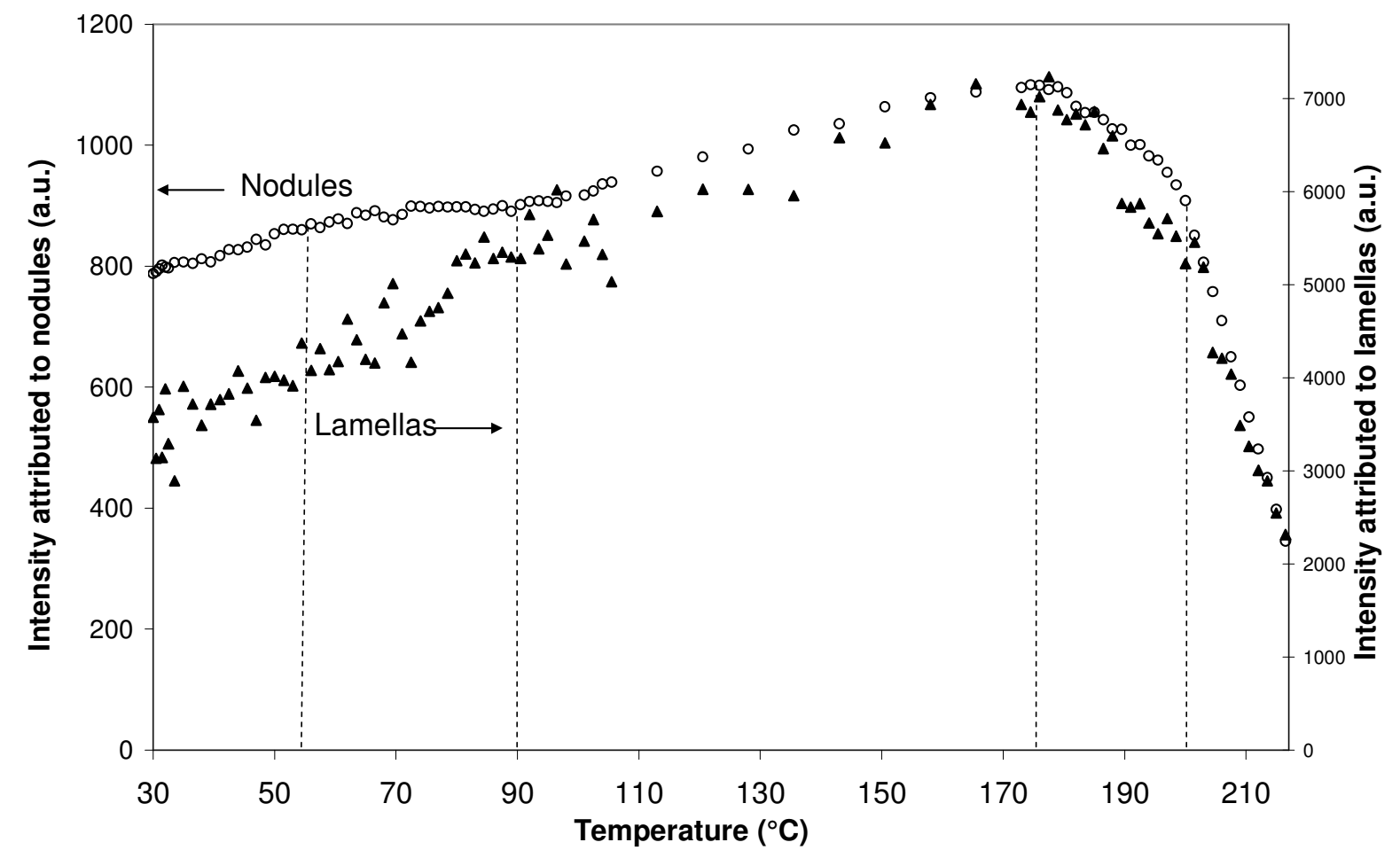

Figure 13. Integrated intensities of the contribution of nodules and lamellae during in-situ SAXS experiments on a mature $2-\mathrm{mm}$ thick plate with increasing temperature, from 30 to $250^{\circ} \mathrm{C}$, at $3^{\circ} \mathrm{C} / \mathrm{min}(1$ data acquisition every $1.5^{\circ} \mathrm{C}$ or $\left.30 \mathrm{~s}\right)$.
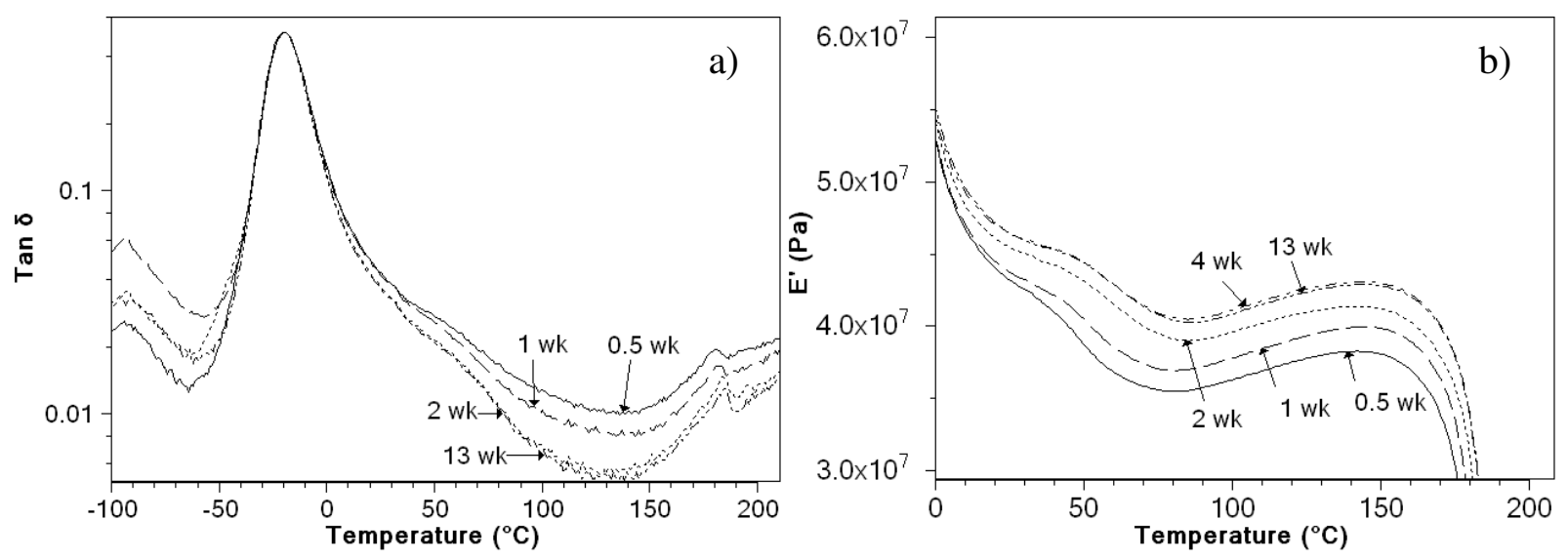

Figure 14. Evolution for a 2-mm thick plate of DMTA a) damping signal and b) elastic modulus E' with maturation time (between 0.5 and 13 weeks at RT) [testing conditions: $0.1 \%$ strain, heating rate: $3^{\circ} \mathrm{C} / \mathrm{min}$, frequency: $\left.1 \mathrm{~Hz}\right]$. 
Tables

Table 1. Tensile properties of a mature $2-\mathrm{mm}$ thick plate during cyclic loading. 4 cycles from 0 to $200 \%$ strain: load at $300 \mathrm{~mm} / \mathrm{min}$, unload at $100 \mathrm{~mm} / \mathrm{min}$ at : $22^{\circ} \mathrm{C}$.

\begin{tabular}{cccc}
\hline Cycle \# & $\begin{array}{c}E_{100 \%} \\
\left(\mathbf{M P a}_{ \pm \mathbf{0 . 2}}\right)\end{array}$ & $\begin{array}{c}\text { Instantaneous } \\
\text { unrecovered } \\
\text { Set }\left(\boldsymbol{\%} \boldsymbol{\Psi}_{\mathbf{1} \%}\right)\end{array}$ & $\mathbf{W}^{\prime \boldsymbol{\prime}}(\mathbf{J})$ \\
\hline 1 & 7.7 & 20 & 1.29 \\
2 & 4.4 & 22 & 0.35 \\
3 & 4.3 & 23 & 0.31 \\
4 & 4.2 & 24 & 0.28 \\
$5^{2}$ & 4.2 & $/$ & $/$
\end{tabular}

$25^{\text {th }}$ load at $300 \mathrm{~mm} / \mathrm{min}$ up to break

Table 2. Thermomechanical characteristics of a mature $2-\mathrm{mm}$ thick plate and of a mature $39-\mathrm{mm}$ diameter cylinder determined by DMTA and extracted from Figure 6. (Testing conditions: 0.1\% strain, heating rate: $3^{\circ} \mathrm{C} / \mathrm{min}$, Frequency: $1 \mathrm{~Hz}$.)

\begin{tabular}{ccccccccc}
\hline & $\mathbf{T} \alpha$ & $\mathbf{T}^{\prime} \mathbf{r}$ & \multicolumn{3}{c}{ tan $\delta$} \\
\cline { 4 - 8 } & $\left({ }^{\circ} \mathbf{C}\right)$ & $\left({ }^{\circ} \mathbf{C}\right)$ & $\mathbf{T} \alpha$ & $\mathbf{2 2}^{\circ} \mathbf{C}$ & $\mathbf{1 4 0}^{\circ} \mathbf{C}$ & $\mathbf{2 2}^{\circ} \mathbf{C}$ & Min value & $\mathbf{1 4 0}^{\circ} \mathbf{C}$ \\
\hline Plate & -21 & 63 & 0.45 & 0.040 & 0.005 & 47 & $40\left(\right.$ at $\left.86^{\circ} \mathrm{C}\right)$ & 43 \\
$\begin{array}{c}\text { Cylinder } \\
\text { shell }\end{array}$ & -20 & 64 & 0.47 & 0.039 & 0.005 & 46 & $40\left(\right.$ at $\left.89^{\circ} \mathrm{C}\right)$ & 43 \\
$\begin{array}{c}\text { Cylinder } \\
\text { core }\end{array}$ & -19 & 85 & 0.61 & 0.035 & 0.004 & 37 & $26\left(\right.$ at $\left.115^{\circ} \mathrm{C}\right)$ & 27 \\
& & & & & & & & \\
\end{tabular}


Table 3. Thermal characteristics of a mature 2-mm thick plate and of a mature 39-mm diameter cylinder determined by DSC and extracted from Figure 1.

\begin{tabular}{ccccccc}
\hline & $\begin{array}{c}\mathbf{T g}_{\text {SS }} \\
\left({ }^{\circ} \mathbf{C}\right)\end{array}$ & $\begin{array}{c}\Delta \mathbf{C p}_{\mathbf{S S}} \\
(\mathbf{J} / \mathbf{g} / \mathbf{K})\end{array}$ & $\begin{array}{c}\mathbf{T r} \\
\left({ }^{\circ} \mathbf{C}\right)\end{array}$ & $\begin{array}{c}\mathbf{T}_{\mathbf{m} 1} \\
\left({ }^{\circ} \mathbf{C}\right)\end{array}$ & $\begin{array}{c}\mathbf{T}_{\mathbf{m} 2} \\
\left({ }^{\circ} \mathbf{C}\right)\end{array}$ & $\begin{array}{c}\Delta \mathbf{H}_{\mathbf{m} 1+2} \\
(\mathbf{J} / \mathbf{g})\end{array}$ \\
\hline Plate & -36 & 0.43 & 53 & 185 & 205 & 10.2 \\
$\begin{array}{c}\text { Cylinder } \\
\text { shell }\end{array}$ & -36 & 0.43 & 48 & 185 & 205 & 10.5 \\
$\begin{array}{c}\text { Cylinder } \\
\text { core }\end{array}$ & -35 & 0.44 & 54 & 210 & 225 & 8.3 \\
& & & & & &
\end{tabular}

Table 4. Fitting parameters extracted from Beaucage model for spheres for SAXS spectra of a mature 2$\mathrm{mm}$ thick plate and of a mature $39-\mathrm{mm}$ diameter cylinder, every $3 \mathrm{~mm}$ from core to shell.

\begin{tabular}{ccccc}
\hline & $\begin{array}{c}R_{g}(\AA) \\
\pm 2\end{array}$ & $\begin{array}{c}d_{2}(\AA) \\
\pm 2\end{array}$ & $k$ & $P$ \\
\hline $\begin{array}{c}\text { Cylinder core } \\
(\mathbf{r}=\mathbf{0})\end{array}$ & 30 & 111 & 0.82 & 3.9 \\
$\mathbf{r = 3}$ & 30 & 111 & 0.87 & 3.9 \\
$\mathbf{r = 6}$ & 30 & 111 & 0.85 & 3.9 \\
$\mathbf{r = 9}$ & 30 & 111 & 0.81 & 3.9 \\
$\mathbf{r = 1 2}$ & 31 & 114 & 0.87 & 3.9 \\
$\mathbf{r = 1 5}$ & 31 & 116 & 0.79 & 3.9 \\
$\begin{array}{c}\text { Cylinder shell } \\
(\mathbf{r}=19.5)\end{array}$ & 32 & 116 & 0.83 & 3.9 \\
Plate & 32 & 117 & 0.87 & 3.9
\end{tabular}


Table 5. Data extracted from Bragg's law on Lorentz-corrected spectra and from 1-D autocorrelation function for a mature 2-mm thick plate and a mature $39-\mathrm{mm}$ diameter cylinder core, every $3 \mathrm{~mm}$ from core to shell.

\begin{tabular}{ccccc}
\hline & $\begin{array}{c}d_{2}^{B}(\AA) \\
\pm 2\end{array}$ & $\begin{array}{c}d_{1}^{B}(\AA) \\
\pm 2\end{array}$ & $\begin{array}{c}L_{p}(\AA) \\
\pm 2\end{array}$ & $\Phi_{1}$ \\
\hline $\begin{array}{c}\text { Cylinder core } \\
(\mathbf{r}=\mathbf{0})\end{array}$ & 108 & 222 & 204 & $13.6 \%$ \\
$\mathbf{r = 3}$ & 108 & 222 & 204 & $13.6 \%$ \\
$\mathbf{r = 6}$ & 108 & 222 & 204 & $13.6 \%$ \\
$\mathbf{r = 9}$ & 109 & 213 & 197 & $13.5 \%$ \\
$\mathbf{r = 1 2}$ & 109 & 207 & 190 & $12.7 \%$ \\
$\mathbf{r = 1 5}$ & 111 & 196 & 182 & $12.8 \%$ \\
$\begin{array}{c}\text { Cylinder shell } \\
(\mathbf{r}=19.5)\end{array}$ & 117 & 211 & 199 & $11.2 \%$ \\
Plate & 115 & 209 & 197 & $11.7 \%$
\end{tabular}

Table 6. Thermal characteristics of a mature $2-\mathrm{mm}$ thick plate determined by DSC at $10^{\circ} \mathrm{C} / \mathrm{min}$. Sample 1 was directly heated from $-80^{\circ} \mathrm{C}$ to $250^{\circ} \mathrm{C}$. Samples 2 to 4 were first heated to 130,195 and $220^{\circ} \mathrm{C}$ respectively, cooled to $-80^{\circ} \mathrm{C}$ and heated to $250^{\circ} \mathrm{C}$. Data are the results of the second heating for samples 2 to 4 . The "intensity" column refers to the large $\mathrm{Tg}_{\mathrm{HS}}$ transition.

\begin{tabular}{|c|c|c|c|c|c|c|c|c|c|}
\hline & & $\begin{array}{l}\operatorname{Tg}_{\text {SS }} \\
\left({ }^{\circ} \mathbf{C}\right)\end{array}$ & $\begin{array}{c}\Delta \mathbf{C p}_{\mathrm{SS}} \\
(\mathrm{J} / \mathrm{g} / \mathbf{K})\end{array}$ & $\begin{array}{c}\mathbf{x}_{\mathrm{h}} \\
(\%)\end{array}$ & $\begin{array}{c}\text { TgHS1 } \\
\left({ }^{\circ} \mathbf{C}\right)\end{array}$ & $\begin{array}{c}\text { Tg } \\
\left({ }^{\circ} \mathbf{C}\right)\end{array}$ & intensity & $\begin{array}{l}\mathbf{T}_{\mathbf{m 1}} \\
\left({ }^{\circ} \mathbf{C}\right)\end{array}$ & $\begin{array}{l}\mathbf{T}_{\mathbf{m} 2} \\
\left({ }^{\circ} \mathbf{C}\right)\end{array}$ \\
\hline Sample 1 & $\begin{array}{l}\text { First heating } \\
\text { (Figure 1) }\end{array}$ & -36 & 0.43 & 17 & 53 & I & + & 185 & 205 \\
\hline Sample 2 & $\begin{array}{c}\text { After cycle } \\
\text { at } 130^{\circ} \mathrm{C}\end{array}$ & -34 & 0.46 & 20 & 54 & I & - & 185 & 205 \\
\hline Sample 3 & $\begin{array}{l}\text { After cycle } \\
\text { at } 195^{\circ} \mathrm{C}\end{array}$ & -32 & 0.49 & 22 & 52 & 103 & - & I & 205 \\
\hline Sample 4 & $\begin{array}{l}\text { After cycle } \\
\text { at } 220^{\circ} \mathrm{C}\end{array}$ & -29 & 0.52 & 26 & 66 & I & ++ & I & I \\
\hline
\end{tabular}


Table 7. Fitting parameters extracted from Beaucage model for spheres and from Bragg's law on Lorentz-corrected spectra for lamellae during in-situ SAXS experiments on a mature 2-mm thick plate with temperature, from 30 to $250^{\circ} \mathrm{C}$, at key temperatures shown on

Figure 12 and Figure 13.

\begin{tabular}{cccccc}
\hline \multicolumn{2}{c}{$\begin{array}{c}\text { Beaucage for } \\
\text { nodules }\end{array}$} & $\begin{array}{c}\text { Bragg for } \\
\text { lamellae }\end{array}$ & nodules & lamellae \\
\hline $\mathbf{T}\left({ }^{\circ} \mathbf{C}\right)$ & $\begin{array}{c}R_{g}(\AA) \\
\pm 1\end{array}$ & $\begin{array}{c}d_{2}(\AA) \\
\pm 1\end{array}$ & $d_{1}^{B}(\AA) \pm 1$ & $\begin{array}{c}\text { Intensity } \\
\text { (a.u.) }\end{array}$ & $\begin{array}{c}\text { Intensity } \\
\text { (a.u.) }\end{array}$ \\
\hline 30 & 34.5 & 121 & 225 & 788 & 74 \\
55 & 35.2 & 122 & 226 & 850 & 108 \\
90 & 38.5 & 129 & 232 & 918 & 129 \\
175 & 39.2 & 131 & 236 & 1099 & 163 \\
200 & 39.9 & 134 & 243 & 934 & 124 \\
215 & 50.2 & 141 & 256 & 345 & 50 \\
250 & ---- & ---- & ---- & ---- & --- \\
& & & & & \\
\hline
\end{tabular}

Table 8. Evolution of the thermal characteristics of a $2-\mathrm{mm}$ thick plate determined by $\mathrm{DSC}$ at $10^{\circ} \mathrm{C} / \mathrm{min}$ during maturation (between 0.5 and 18 weeks).

\begin{tabular}{ccccccc}
\hline $\begin{array}{c}\text { Time } \\
\text { (weeks) }\end{array}$ & $\begin{array}{c}\mathbf{T g}_{\mathrm{HS1}} \\
\left({ }^{\circ} \mathbf{C}\right)\end{array}$ & $\begin{array}{c}\mathbf{T}_{\mathbf{m} 1} \\
\left({ }^{\circ} \mathbf{C}\right)\end{array}$ & $\begin{array}{c}\mathbf{T}_{\mathbf{m} 2} \\
\left({ }^{\circ} \mathbf{C}\right)\end{array}$ & $\begin{array}{c}\Delta \mathbf{H}_{\mathbf{m} 1} \\
(\mathbf{J} / \mathbf{g})\end{array}$ & $\begin{array}{c}\Delta \mathbf{H}_{\mathbf{m} 2} \\
(\mathbf{J} / \mathbf{g})\end{array}$ & $\begin{array}{c}\Delta \mathbf{H}_{\mathbf{m} 1+2} \\
(\mathbf{J} / \mathbf{g})\end{array}$ \\
\hline 0.5 & 41 & 183 & 201 & 4.1 & 4.8 & 8.9 \\
1 & 43 & 183 & 201 & 4.2 & 4.6 & 8.8 \\
2 & 46 & 185 & 203 & 4.2 & 5.4 & 9.6 \\
13 & 53 & 185 & 205 & 4.3 & 5.9 & 10.2 \\
18 & 52 & 185 & 205 & 4.4 & 5.8 & 10.2
\end{tabular}


Table 9. Evolution of thermomechanical characteristics of a 2-mm thick plate determined by DMTA during maturation (between 0.5 and 13 weeks). (Testing conditions: $0.1 \%$ strain, heating rate: $3^{\circ} \mathrm{C} / \mathrm{min}$, Frequency: $1 \mathrm{~Hz}$.

\begin{tabular}{cccc|cc}
\hline $\begin{array}{c}\text { Time } \\
(\mathbf{w k})\end{array}$ & $\begin{array}{c}\mathbf{T}^{\prime} \mathbf{r} \\
\left({ }^{\circ} \mathbf{C}\right)\end{array}$ & $\begin{array}{c}\text { E' } \\
(\mathbf{M P a})\end{array}$ & $\tan \boldsymbol{\delta}$ & $\begin{array}{c}\text { E' } \\
(\mathbf{M P a})\end{array}$ & $\tan \boldsymbol{\delta}$ \\
\hline \multicolumn{2}{c}{$\mathbf{2 2}^{\circ} \mathbf{C}$} & \multicolumn{2}{|c}{$\mathbf{1 4 0}^{\circ} \mathbf{C}$} \\
\hline 0.5 & 51 & 44 & 0.046 & 38 & 0.010 \\
1 & 56 & 44 & 0.045 & 40 & 0.008 \\
2 & 61 & 46 & 0.040 & 41 & 0.006 \\
4 & 63 & 47 & 0.040 & 43 & 0.005 \\
9 & 64 & 47 & 0.039 & 43 & 0.005 \\
13 & 63 & 47 & 0.040 & 43 & 0.005 \\
& & & & &
\end{tabular}

Table 10. Evolution of tensile properties of the 2-mm thick plate during cyclic loading at $22^{\circ} \mathrm{C}$ during maturation (between 0.5 and 13 weeks). Results from the first cycle (load at $300 \mathrm{~mm} / \mathrm{min}$ from 0 to $200 \%$ strain; unload at $100 \mathrm{~mm} / \mathrm{min}$ ) and final properties after $5^{\text {th }}$ load.

\begin{tabular}{|c|c|c|c|c|c|}
\hline $\begin{array}{l}\text { Time } \\
\text { (wk) }\end{array}$ & $\begin{array}{c}E_{100 \%} \\
\left(\mathbf{M P a} \mathbf{a}_{ \pm \mathbf{0 . 2}}\right)\end{array}$ & $\begin{array}{c}\text { Instantaneous } \\
\text { unrecovered } \\
\text { Set }^{3}(\% \pm 1 \%)\end{array}$ & $\begin{array}{l}\mathbf{W}^{\prime \prime} \\
(\mathrm{J})\end{array}$ & $\begin{array}{c}\text { Stress at } \\
\text { break } \\
\left(\mathbf{M P a}_{ \pm 2}\right)\end{array}$ & $\begin{array}{c}\text { Strain at } \\
\text { break } \\
(\% \pm 40 \%)\end{array}$ \\
\hline 0.5 & 6.8 & 24 & 1.18 & 24 & 530 \\
\hline 1 & 7.3 & 21 & 1.24 & 26 & 450 \\
\hline 4 & 7.7 & 21 & 1.30 & 24 & 440 \\
\hline 9 & 7.6 & 20 & 1.28 & 22 & 390 \\
\hline 13 & 7.7 & 20 & 1.29 & 23 & 410 \\
\hline
\end{tabular}


Table 11. Fitting parameters extracted from Beaucage model for SAXS spectra of a 2-mm thick plate after 1 and 23 weeks maturation.

\begin{tabular}{ccccc}
\hline & $\begin{array}{c}R_{g}(\AA) \\
\pm 1\end{array}$ & $\begin{array}{c}d_{2}(\AA) \\
\pm 1\end{array}$ & $k$ & $P$ \\
& 31 & 116 & 0.83 & 3.8 \\
\hline after 1 week & 31 & 117 & 0.83 & 3.9
\end{tabular}

Table 12. Evolution of the thermomechanical characteristics of the core of a 39-mm diameter cylinder determined by DMTA during maturation. (testing conditions: $0.1 \%$ strain, heating rate: $3^{\circ} \mathrm{C} / \mathrm{min}$, frequency: $1 \mathrm{~Hz}$.$) .$

\begin{tabular}{lcccccc}
\hline & $\mathbf{T} \alpha$ & \multicolumn{3}{c}{$\tan \delta$} & & \multicolumn{2}{c}{ E' (MPa) } \\
\cline { 3 - 7 } & $\left({ }^{\circ} \mathbf{C}\right)$ & $\mathbf{T} \alpha$ & $\mathbf{2 2}^{\circ} \mathbf{C}$ & $\mathbf{1 4 0}^{\circ} \mathbf{C}$ & $\mathbf{2 2}^{\circ} \mathbf{C}$ & $\mathbf{1 4 0}^{\circ} \mathbf{C}$ \\
\hline after 4 weeks & -20 & 0.62 & 0.046 & 0.023 & 34 & 24 \\
after 8 weeks & -19 & 0.62 & 0.038 & 0.012 & 36 & 27 \\
after 13 weeks & -19 & 0.61 & 0.035 & 0.006 & 37 & 27
\end{tabular}


Table 13. Fatigue properties at $27 \mathrm{~Hz}, \sigma_{\max }=3.35 \mathrm{MPa}$ and $\mathrm{R}=0.1$ during maturation (between 0.5 and 13 weeks). The values at $22^{\circ} \mathrm{C}$ come from the 10 first cycles at the beginning of the test. Values measured when the sample stabilized in temperature are also reported.

\begin{tabular}{|c|c|c|c|c|c|}
\hline & $\begin{array}{l}\text { Time } \\
\text { (wk) }\end{array}$ & $\begin{array}{l}\text { W' } \\
\text { (J) }\end{array}$ & $\begin{array}{c}\mathbf{E}_{\text {dyn }} \\
\text { (MPa) }\end{array}$ & $\tan \delta$ & $\begin{array}{l}\mathbf{T}_{\text {stab }} \\
\left({ }^{\circ} \mathbf{C}\right)\end{array}$ \\
\hline \multirow{3}{*}{$\begin{array}{l}\stackrel{0}{N} \\
\stackrel{N}{*}\end{array}$} & 4 & 0.93 & 41.4 & 0.126 & - \\
\hline & 9 & 0.87 & 43.0 & 0.123 & - \\
\hline & 13 & 0.87 & 42.7 & 0.122 & - \\
\hline \multirow{3}{*}{$\frac{\vec{E}}{\vec{E}}$} & $4^{4}$ & 1.07 & 30.0 & 0.105 & n.s. \\
\hline & 9 & 0.80 & 30.5 & 0.080 & 145 \\
\hline & 13 & 0.78 & 30.7 & 0.079 & 140 \\
\hline
\end{tabular}

${ }^{4}$ at $\mathrm{T}=140^{\circ} \mathrm{C}$. n.s.: non stabilized in temperature.

\section{References}

(1) Seymour, R. W.; Cooper, S. L. Macromolecules 1973, 6, 48-53.

(2) Koberstein, J. T.; Russel, T. P. Macromolecules 1986, 19, 714-720.

(3) Leung, L. M.; Koberstein, J. T. Macromolecules 1986, 19, 706-713.

(4) Macosko, C.W.. Fundamentals of reaction injection molding, Eds.; Hanser: New York, 1989.

(5) Ryan, A. J.; Willkomm, W. R.; Bergstrom, T. B.; Macosko, C. W.; Koberstein, J. T.; Yu, C. C. Macromolecules 1991, 24, 2883-2889. 
(6) Chu, B.; Gao, T.; Li, Y. J.; Wang, J.; Desper, C. R.; Byrne, C. A. Macromolecules 1992, 25, 57245729.

(7) Yang, Z. H.; Hu, J. L.; Liu, Y. Q.; Yeung, L. Y. Mater. Chem. Phys. 2006, 98, 368-372.

(8) Jung, H. C.; Kang, S. J.; Kim, W. N.; Lee, Y.; Choe, K. H.; Hong, S.; Kim, S. J. Appl. Polym. Sci. 2000, 78, 624-630.

(9) Tsai, Y. M.; Yu, T. L.; Tseng, Y. H. Polym. Int. 1998, 47, 445-450.

(10) Petrovic, Z. S.; Javni, I.; Divjakovic, V. J. Polym. Sci. Pol. Phys. 1998, 36, 221-235.

(11) Prisacariu, C.; Agherghinei, I. J.M.S. Pure Appl. Chem. 2000, 37, 785-806.

(12) Martin, D. J.; Warren, L. A. P.; Gunatillake, P. A.; McCarthy, S. J.; Meijs, G. F.; Schindhelm, K. Biomaterials 2001, 22, 973-978.

(13) Sonnenschein, M.; Wendt, B. L.; Schrock, A. K.; Sonney, J.; Ryan, A. J. Polymer 2008, 49, 934942.

(14) Saiani, A.; Novak, A.; Rodier, L.; Eeckhaut, G.; Leenslag, J.; Higgins, J. Macromolecules 2007, $40,7252-7262$

(15) Ratner, S. B.; Korobov, V. L. Mekhanika Polimerov 1965, 1, 93-100.

(16) Ratner, S. B.; Buglo, S. T. Mekhanika Polimerov 1969, 3, 465-469.

(17) Kogelnik, H. J.; Huang, H. H.; Barnes, M.; Meichsner, R. 33rd annual Polyurethane technical/marketing conference 1990, Orlando, FL.

(18) Galetz, M.; Goetz, C.; Adam, P.; Glatzel, U. Adv. Eng. Mater. 2007, 9, 1089-1096.

(19) Mead, J.; Singh, S.; Roylance, D.; Patt, J. Polym. Eng. Sci. 1987, 27, 131-140.

(20) Gillis, H. R.; Hurst, A. T.; Ferrarini, L. J.; Watts A J. Elastomers and Plastics 1984, 16, 291-306. 
(21) Hepburn, C.. Polyurethane elastomers, Eds.; Elsevier Applied Science: 2ème édition, London, 1991.

(22) Medalia, A. I. Rubber Chem. Technol. 1991, 64, 481-492.

(23) Dieter, J. W.; Byrne, C. A. Polym. Eng. Sci. 1987, 27, 673-683.

(24) Camberlin, Y.; Pascault, J. P. J. Polym. Sci. Pol. Chem. Ed. 1983, 21, 415-423.

(25) Zha, L. S.; Wu, M. Y.; Yang, J. J. J. Appl. Polym. Sci. 1999, 73, 2895-2902.

(26) Mullins, L. Rubber Chem. Technol. 1969, 42, 339-362.

(27) Cuvé, L.; Pascault, J.; Boiteux, G. Polymer 1992, 33, 3957-3967.

(28) Cuvé, L.; Pascault, J. P.; Boiteux, G.; Seytre, G. Polymer 1991, 32, 343-352.

(29) Koberstein, J. T.; Galambos, A. F.; Leung, L. M. Macromolecules 1992, 25, 6195-6204.

(30) Saiani, A.; Rochas, C.; Eeckhaut, G.; Daunch, W.; Leenslag, J.; Higgins, J. Macromolecules 2004, 37, 1411-1421.

(31) Unal, S.; Ozturk, G.; Sisson, K.; Long, T. E. J. Polym. Sci. Pol. Chem. Ed. 2008, 46, 6285-6295.

(32) Tonelli, C.; Trombetta, T.; Maccone, P. J. Polym. Sci. Pol. Chem. 1999, 37, 1473-1487.

(33) Christenson, E. M.; Anderson, J. M.; Hiltner, A.; Baer, E. Polymer 2005, 46, 11744-11754.

(34) Marckmann, G.; Verron, E.; Gornet, L.; Chagnon, G.; Charrier, P.; Fort, P. J. Mech. Phys. Solids 2002, 50, 2011-2028.

(35) Qi, H. J.; Boyce, M. C. Mech. Mater. 2005, 37, 817-839.

(36) Aneja, A.; Wilkes, G. L. Polymer 2003, 44, 7221-7228.

(37) Tocha, E.; Janik, H.; Debowski, M.; Vancso, G. J. J. Macromol. Sci. B 2002, 41, 1291-1304. 
(38) Glatter, O. \& Kratky, O.. Small angle X-ray scattering, Eds.; Academic Press: London, New York, 1982.

(39) Beaucage, G.; Schaefer, D. W. Journal of Non-Crystalline Solids 1994, 172-174, 797-805.

(40) Laity, P. R.; Taylor, J. E.; Wong, S.; Khunkamchoo, P.; Norris, K.; Cable, M.; Andrews, G.; Johnson, A.; Cameron, R. Polymer 2004, 45, 7273-7291.

(41) Finnigan, B.; Jack, K.; Campbell, K.; Halley, P.; Truss, R.; Casey, P.; Cookson, D.; King, S.; Martin, D. Macromolecules 2005, 38, 7386-7396.

(42) Saiani, A.; Daunch, W.; Verbeke, H.; Leenslag, J.; Higgins, J. Macromolecules 2001, 34, 90599068. 


\section{For Table of Contents Use Only}

Maturation of Crosslinked Segmented Polyurethanes. Morphological changes and consequences on Elastic Properties and Thermal Compressive Fatigue

Pascal G. Pichon, Laurent David, Françoise Méchin, Henry Sautereau

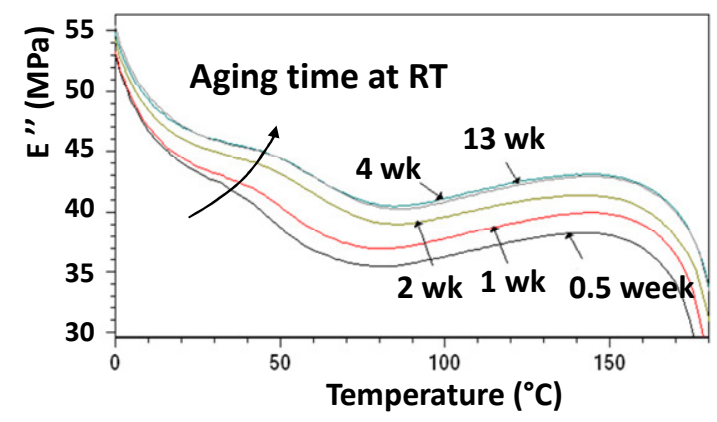

